\title{
Psychostimulants Depress Excitatory Synaptic Transmission in the Nucleus Accumbens via Presynaptic D1-Like Dopamine Receptors
}

\author{
Saleem M. Nicola, ${ }^{1, a}$ Samuel B. Kombian, ${ }^{2, a}$ and Robert C. Malenka² \\ ${ }^{1}$ Graduate Program in Neuroscience and ${ }^{2}$ Center for Neurobiology and Psychiatry and Departments of Psychiatry and \\ Physiology, University of California, San Francisco, California 94143
}

\begin{abstract}
The effects of dopamine (DA) and the psychostimulants cocaine and amphetamine on excitatory transmission in the nucleus accumbens (NAc) were examined in rat NAc slices using both extracellular-field and whole-cell patch-clamp recording. DA, cocaine, and amphetamine reversibly reduced the excitatory synaptic responses (EPSPs/EPSCs) elicited by stimulation of prelimbic cortical afferents. DA and amphetamine increased paired-pulse facilitation, reduced the frequency of spontaneous miniature EPSCs (mEPSCs), and had no effect on mEPSC amplitude, suggesting a presynaptic mechanism for the observed reduction in excitatory synaptic transmission. The effects of DA and amphetamine were attenuated by the D1 receptor antagonist $\mathrm{SCH} 23390$ but not by the D2 receptor antagonist sulpiride. The broad-spectrum DA receptor agonist 6,7-ADTN mimicked the effects of DA and the psychostimulants, but neither the D1 receptor agonists SKF38393 and SKF81297 nor the D2 receptor agonist quinpirole caused a
\end{abstract}

significant reduction in EPSP magnitude. SKF38393 at a higher concentration $(100 \mu \mathrm{M})$ was effective in reducing the EPSP, however, and this reduction was sensitive to $\mathrm{SCH} 23390$. There was no difference in the effects of DA in cells from mutant mice lacking D1a receptors and cells from wild-type control mice. Unilaterally lesioning the dopaminergic afferents to the NAC using 6-hydroxydopamine attenuated the amphetamineinduced reduction in EPSP magnitude in slices from the lesioned hemisphere but not the control (unlesioned) hemisphere. These results indicate that DA and psychostimulants (acting indirectly by increasing endogenous extracellular DA levels) reduce excitatory synaptic transmission in the NAc by activating presynaptic DA receptors with D1-like properties.

Key words: amphetamine; cocaine; miniature excitatory postsynaptic currents; dopamine; dopamine receptors; nucleus accumbens; excitatory synaptic transmission; presynaptic modulation; 6-hydroxydopamine
The nucleus accumbens (NAc), which is often described as the ventral striatum, receives a major dopaminergic input from cells located in the ventral tegmental area (VTA) (Swerdlow and Koob, 1987; Pennartz et al., 1994) and thus is considered a principal component of the mesolimbic dopamine (DA) system (Paxinos and Watson, 1986; Swerdlow and Koob, 1987). The limbic inputs to this nucleus are excitatory and originate from both cortical and subcortical limbic areas including the subiculum, hippocampus, cingulate cortex, prefrontal cortex, and amygdala complex (Nauta et al., 1978; DeFrance et al., 1985a; Christie et al., 1987; Sesack et al., 1989; Brog et al., 1993). Activation of these afferents elicits fast monosynaptic excitatory postsynaptic responses that are mediated by both non-NMDA and NMDA glutamate receptors (Chang and Kitai, 1986; Uchimura et al., 1989; Pennartz et al., 1990; Uchimura and North, 1991; Pennartz et al., 1992a; O'Donnell and Grace, 1993, 1995; Kombian and Malenka, 1994a). The principal cells of the NAc are medium spiny GABAergic neurons (Chronister et al., 1981; DeFrance et al.,

\footnotetext{
Received Oct. 4, 1995; revised Nov. 21, 1995; accepted Nov. 28, 1995.

This work was supported by grants (to R.C.M.) from the National Institute on Drug Abuse and the National Institute of Mental Health. S.M.N. was supported by a National Institute of Mental Health predoctoral fellowship, and S.B.K. was supported by a postdoctoral fellowship from the Human Frontiers Science Program Organization. We are grateful to Drs. S. Tonegawa and $\mathrm{M}$. Xu for their generous gift of D1a mutant mice, and to Dr. M. Crair for help with stereotaxic injections.

Correspondence should be addressed to Robert C. Malenka, Department of

Psychiatry, LPPI, Box 0984, University of California, San Francisco, CA 94143-0984.

Dr. Kombian's present address: Neuroscience Research Group, University of Calgary, Calgary, Alberta, Canada T2N 4N1.

aThese authors contributed equally to this work.

Copyright 1996 Society for Neuroscience $0270-6474 / 96 / 161591-14 \$ 05.00 / 0$
}

1985a; O'Donnell and Grace, 1993) that exhibit extensive collateral interaction within the NAc (Christie et al., 1987; Pennartz et al., 1994). These cells are generally quiescent both in vivo and in vitro with very negative resting potentials (White and Wang, 1984; Yang and Mogenson, 1984; Higashi et al., 1989; Uchimura and North, 1991) and are therefore strongly dependent on excitatory inputs to generate their output.

The NAc serves as an important site of action for the rewarding effects of psychostimulant drugs such as cocaine and amphetamine (Koob and Bloom, 1988; Nestler, 1992). These drugs also induce behavioral sensitization, which refers to an augmentation of their locomotor stimulatory activity with repetitive administration (Kalivas and Stewart, 1991). Both the rewarding properties of psychostimulants and the behavioral sensitization induced by them depend on excitatory synaptic transmission (Hamilton et al., 1986; Pulvirenti et al., 1991, 1992; Wolf and Khansa, 1991; Karler and Calder, 1992; Wolf and Jeziorski, 1993) as well as on dopaminergic transmission (Koob and Bloom, 1988; Kalivas and Stewart, 1991; Nestler, 1992).

Psychostimulants are thought to induce their behavioral effects by inhibiting the reuptake of DA into the presynaptic terminal and in the case of amphetamine by promoting the nonvesicular release of DA, thereby increasing extracellular levels of DA (Wise and Bozarth, 1987; Kuhar et al., 1991; Seiden et al., 1993; Sulzer et al., 1995). Despite the knowledge of the biochemical actions of psychostimulants and the documented importance of the NAc as a locus for their behavioral effects, the basic effects of DA and psychostimulants on synaptic transmission within the NAc are not well understood. Relatively few in vitro studies have been per- 
formed (Chang and Kitai, 1986; Higashi et al., 1989; Uchimura et al., 1989; Pennartz et al., 1990; Uchimura and North; 1991; Pennartz et al., 1992a,b; O’Donnell and Grace, 1993, 1994) and some of the most relevant results from these studies are conflicting (Pennartz et al., 1992a,b; O’Donnell and Grace, 1994; Higashi et al., 1989). Here we attempt to clarify the synaptic effects of DA and psychostimulants within the core region of the NAc by pharmacologically characterizing the actions of DA, cocaine, and amphetamine on evoked excitatory responses and on spontaneous miniature EPSCs (mEPSCs).

Parts of this paper have been published previously in abstract form (Kombian and Malenka, 1994b; Nicola et al., 1995).

\section{MATERIALS AND METHODS}

Slice preparation and recording techniques. The methods used for this study were largely identical to those described previously (Kombian and Malenka, 1994a). Sprague-Dawley rats (13-40 d postnatal) were used for all experiments except those involving mutant mice or 6-hydroxydopamine (6-OHDA) lesioned rats. Animals were completely anesthetized with Halothane and parasagittal NAc slices ( $400 \mathrm{~mm}$ thick) were prepared from both hemispheres using a vibratome. Throughoul the procedure, the tissue was maintained in ice-cold artificial CSF, which was bubbled continuously with $95 \% \mathrm{O}_{2} / 5 \% \mathrm{CO}_{2}$. The composition of the CSF was (in mM): $126 \mathrm{NaCl}, 1.6 \mathrm{KCl}, 1.2 \mathrm{NaH}_{2} \mathrm{PO}_{4}, 1.2 \mathrm{MgCl}_{2}, 2.5 \mathrm{CaCl}_{2}, 18$ $\mathrm{NaHCO}_{3}$, and 11 glucose. After at least $1 \mathrm{hr}$ incubation at room temperature, slices were transferred to a recording chamber and submerged beneath continuously flowing ( $2 \mathrm{ml}$ per $\mathrm{min}$ ) CSF at a temperature of $26-29^{\circ} \mathrm{C}$. Because of the presence of strong GABAcrgic inhibition in the NAc, picrotoxin $(25 \mu \mathrm{M})$ was present in the CSF for all experiments. Prelimbic cortical afferents were activated at $0.1 \mathrm{~Hz}$ by placing a bipolar stainless steel microelectrode at the prelimbic cortex-NAc border, and recordings were made in the core region of the NAc using the anterior commissure and lateral ventricles as anatomical markers.

All recordings were performed using either an Axoclamp 2A or Axopatch 2D amplifier (Axon Instruments, Foster City, CA). For field recordings, glass micropipettes were filled with $3 \mathrm{M} \mathrm{NaCl}$. For whole-cell current-clamp recordings (Blanton et al., 1989), micropipettes (8-15 $\mathrm{M} \Omega$ ) were filled with a solution consisting of (in $\mathrm{mM}$ ): 117.5 potassium gluconate, 17.5 potassium methylsulfate, $8 \mathrm{NaCl}, 10 \mathrm{HEPES}, 0.2 \mathrm{EGTA}$, $5 \mathrm{Mg}$-ATP, and $0.2 \mathrm{GTP}$, pH 7.2-7.4. In some cases the potassium gluconate was replaced with potassium methylsulfate. Input resistance was monitored continuously throughout all experiments by applying a $50-100 \mathrm{pA}(100 \mathrm{msec})$ negative current pulse at least $150 \mathrm{msec}$ after synaptic stimulation. Appropriate current was injected via the bridge circuit to maintain a constant membrane potential throughout each experiment.

For whole-cell voltage-clamp recordings, the pipette solution consisted of (in $\mathrm{mM}$ ): 117.5 cesium gluconate, 17.5 cesium chloride, $8 \mathrm{NaCl}, 10$ HEPES, 0.2 EGTA, $5 \mathrm{Mg}$-ATP, and 0.2 GTP, pH 7.2-7.4. Cells were clamped near their resting potential (holding potential, $V_{\mathrm{h}}=-80 \mathrm{mV}$ ) in the continuous single-electrode voltage-clamp mode. At this potential, the EPSC was mediated mainly by non-NMDA receptors (Kombian and Malenka, 1994a). Input resistance was monitored continuously by applying a $10 \mathrm{mV}(100 \mathrm{msec})$ hyperpolarizing step $100-200 \mathrm{msec}$ after synaptic stimulation. Spontaneous mEPSCs were collected under the same conditions, except that $1.5 \mu \mathrm{M}$ tetrodotoxin (TTX) was present in the perfusion medium throughout the experiment.

6-OHDA lesion experiments. Female Wistar rats (160-175 gm) were anesthetized with ketamine $(60 \mathrm{mg} / \mathrm{kg}$, i.p. ) and acepromazine $(0.6 \mathrm{mg} / \mathrm{kg}$, i.p.) and ventilated with a mixture of $\mathrm{O}_{2}, \mathrm{~N}_{2} \mathrm{O}$, and Halothane while stereotaxic injections of 6-OHDA were made into the left medial forebrain bundle (Ungerstedt, 1971). Injection coordinates (König and Klippel, 1963; Paxinus and Watson, 1986) were $4.4 \mathrm{~mm}$ posterior to Bregma, $1.2 \mathrm{~mm}$ lateral to the midline, and $8.5 \mathrm{~mm}$ ventral to the top of the skull at Lambda. Freshly prepared 6-OHDA solution $(8 \mu \mathrm{g} / \mu \mathrm{l}$ in $0.1 \%$ ascorbic acid) was placed in a glass micropipette (tip diameter $100 \mu \mathrm{m}$ ), and $4 \mu \mathrm{l}$ was injected over 2-3 min. After $5 \mathrm{~min}$, the pipette was removed and the animal was allowed to recover. To assess the effectiveness of the lesion, animals were tested for rotation behavior $10 \mathrm{~d}$ after surgery by administering apomorphine $(1 \mathrm{mg} / \mathrm{kg}$, i.p.) and counting the number of rotations contralateral to the lesion made during a $5 \mathrm{~min}$ period heginning $15 \mathrm{~min}$ after the apomorphine injection (Hefti et al., 1979). Slices were cut 10-15 $d$ after the rotation test.
Drug application. All drugs were applied by bath perfusion with CSF containing the final concentration of the drug. Appropriate stock solutions of drugs were made and diluted with CSF just before application. All stock solutions were made daily and at concentrations at least 1000 -fold higher than those applied to the slices. Antagonists were applied at least $10 \mathrm{~min}$ before the addition of agonist in the continued presence of antagonist. CGP35348 was dissolved directly in CSF. DA $\mathrm{HCl},( \pm)$-norepinephrine $\mathrm{HCl}$, and ( \pm )-2-amino-6,7-dihydro-1,2,3,4tetrahydronaphthalene $\mathrm{HBr}(6,7-\mathrm{ADTN})$ were prepared in a water stock solution containing sodium metabisulfite $(50 \mathrm{~mm}$ in stock solutions, $50 \mu \mathrm{M}$ in the final solution) to protect them from oxidation. $S(-)$-sulpiride and 6-cyano-7-nitroquinoxaline-2,3-dione (CNOX) were prepared in dimethyl sulfoxide, and TTX was prepared in ethanol. Cocaine, $\mathrm{S}(+)$ amphetamine, $\mathrm{R}(+)-\mathrm{SCH} 23390, \quad(-)$-quinpirole, SKF38393, $( \pm)$ SKF81297, S(-)-propranolol, phentolamine mesylate, and serotonin $\mathrm{HCl}$ were all made up in water. Chemicals were from Sigma (St. Louis, MO) or Research Biochemicals (Natick, MA).

Data acquisition, analysis, and statistics. Data were collected and andlyzed $(3-10 \mathrm{KHz}$ sampling rate) using custom-written software. Both the EPSP/EPSC amplitude and the initial slope of the EPSP, calculated using a least square regression, were monitored as a measure of synaptic response. Each point on the illustrated graphs is the mean of six successive responses. Each representative data trace is the mean of 10-11 successive responses.

For experiments studying mEPSCs, $0.1 \mathrm{~Hz}$ negative-voltage pulses were used throughout the experiment to monitor input and access resistance. Data were continuously digitized at $10 \mathrm{KHz}$ and stored on a computer hard disk. After the experiment, mEPSCs were detected using software (generously provided by J. Steinbach, Washington University) that used the fast rise time of mEPSCs to determine the presence of each putative mEPSC. If the amplitude of the event fell within the limits expected for mEPSCs (usually 3-70 pA), the event was counted as an mEPSC. The ability of the program to detect genuine mEPSCs was always checked by eye at several times during the experiment, and a plot of input resistance and access resistance over time was always computed. Average mEPSC amplitude and frequency were computed in 1 min bins.

For all slice experiments, the experimental comparison was between the magnitude of the baseline responses and the magnitude of the responses in agonist. For each individual experiment, two data points were computed for use in the statistical analysis: the average of all points in the $10 \mathrm{~min}$ baseline and the average of all points in a $3 \mathrm{~min}$ period (which was the same for all experiments in one set of comparisons) during agonist application. Thus, all experiments involved repeated measures of one factor: presence of agonist. When this was the only experimental factor, a paired $t$ test was used to determine whether there was a significant effect of the agonist on the magnitude of the response compared with the baseline magnitude. In some experiments, an additional comparison such as the degree to which the agonist-induced change was affected by an antagonist was also made. In these cases, the statistical test used was a two-factor repeated-measures ANOVA with repeated measures on one factor (presence of agonist) but not on the other (presence of antagonist). The ANOVA revealed whether the agonist caused a change in the response as well as whether the antagonist significantly altered the degree of change induced by the agonist. (In no case did the ANOVA reveal a significant difference between the different levels of the nonrepeated-measures factor, presence of antagonist, and therefore these results are not reported.)

All statistical calculations were based on non-normalized data; howcver, graphs of the averages of experiments, the calculated percentage change, and the calculated SEM of the percentage change are all based on data normalized to a $10 \mathrm{~min}$ baseline. All statistical tests assumed that the underlying distribution of the data was normal unless the data were obviously skewed. This was the case for only one experiment (see Fig. $5 C$ ), and a nonparametric test was used in this case. ANOVAs were calculated using SigmaStat (Jandel Scientific, San Rafael, CA); $p \leq 0.05$ was considered statistically significant.

\section{RESULTS}

Extracellular field recording in the presence of picrotoxin $(25 \mu \mathrm{M})$ revealed that electrical stimulation at the border of the prelimbic cortex and the NAc resulted in a biphasic response (Fig. 1A) (Pennartz et al., 1992a). Bath application of the ionotropic glutamate receptor antagonist CNQX $(10 \mu \mathrm{M})$ abolished the later of the two negative potentials $(n=5)$, demonstrating that this 

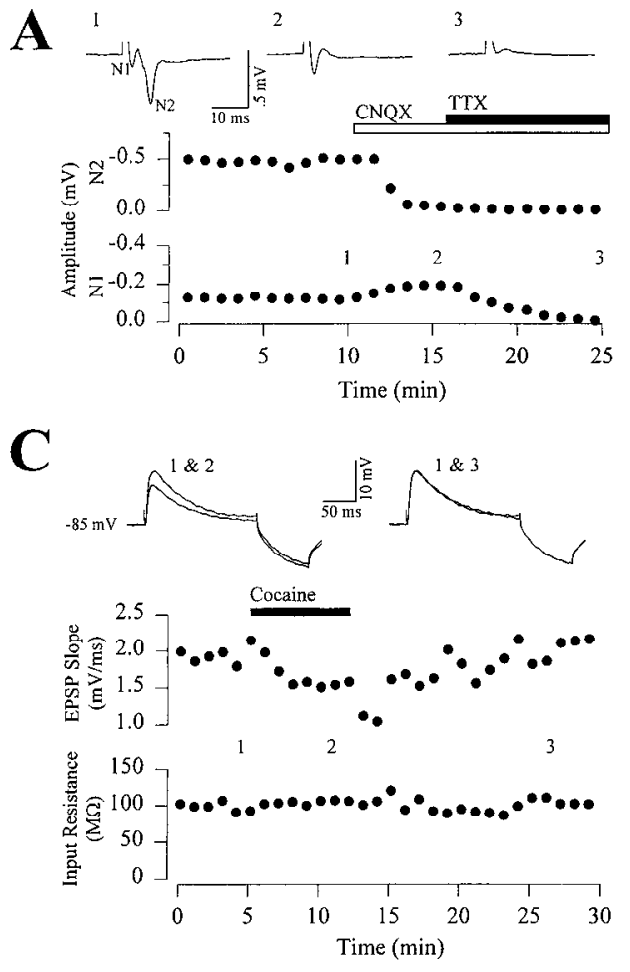

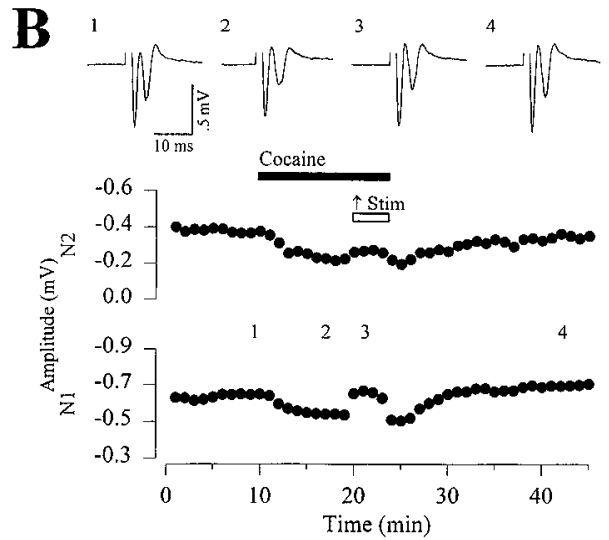

D

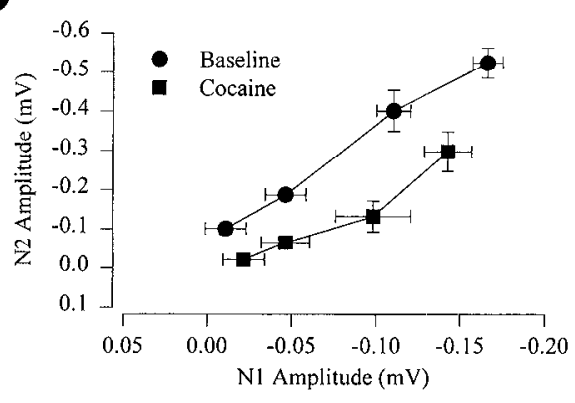

Figure 1. Cocaine reduces evoked synaptic responses. $A$, An extracellular recording of a typical biphasic potential, dcmonstrating that the later event (N2) was sensitive to CNQX $(10 \mu \mathrm{M})$, whereas the earlier event (N1) was sensitive to TTX (1 $\mu \mathrm{M}, n=5)$. In this and all subsequent figures, sample data traces (averages of 10-11 consecutive sweeps) are superimposed above graphs representing measurements taken from the raw sweeps, in this case $\mathrm{N} 2$ amplitude (top) and $\mathrm{N} 1$ amplitude (bottom). The representative sweeps are taken at the times indicated by the numbers on the graphs. $B$, An experiment demonstrating the reduction in the synaptic (N2) and nonsynaptic (N1) potentials causcd by application of $30 \mu \mathrm{M}$ cocaine (solid bar). In the presence of cocaine, the stimulus strength was increased such that the N1 amplitude matched the baseline N1 amplitude (open bar). $C$, In a typical current-clamped cell, $30 \mu \mathrm{M}$ cocaine depressed the initial slope of the EPSP but not the input resistance as measured by the amplitude of the voltage response to a $-0.1 \mathrm{nA}$ current injection. $D$, A representative inputoutput curve $(n=7)$ for responses before the application of cocaine (circles) and in the presence of $30 \mu \mathrm{M}$ cocaine (squares). Error bars represent standard deviations. component $(N 2$, Fig. $1 A)$ resulted from excitatory synaptic transmission. The earlier component $(N 1$, Fig. $1 A$ ) was not diminished by CNQX but was eliminated by the Na channel blocker TTX $(1 \mu \mathrm{M}, n=5)$. These results demonstrate that the amplitude of N1 is a measure of the direct, nonsynaptic generation of action potentials, whereas the amplitude of N2 is a measure of excitatory postsynaptic responses (Malenka and Kocsis, 1988).

\section{Cocaine, amphetamine, and DA inhibit excitatory synaptic transmission}

Cocaine has at least two pharmacclogical actions. It blocks the reuptake of monoamines such as DA (Kuhar et al., 1991; Cunningham et al., 1992), and it exerts a local anesthetic effect (Dunwiddie et al., 1988). Bath application of cocaine $(30 \mu \mathrm{M})$ reversibly depressed the synaptic response but also decreased N1 amplitude (Fig. $1 B$ ). When the stimulus strength was increased, however, such that the N1 amplitude in the presence of cocaine was identical to the baseline N1 amplitude, the synaptic response remained depressed (Fig. $1 B$ ), indicating that the synaptic depression induced by cocaine is not attributable to its local anesthetic actions alonc. To confirm this rcsult, wc mimicked the local anesthetic reduction in the number of axons firing action potentials by stimulating the slice with a range of stimulus intensities both before and after the application of cocaine (Fig. 1D). In six of seven experiments, the plot of $\mathrm{N} 2$ versus $\mathrm{N} 1$ amplitude was shifted to the right by cocaine $(30 \mu \mathrm{M})$. Such a shift is inconsistent with the superimposable curves that would be expected if cocaine had no effect on synaptic transmission other than to reduce action-potential activation. In addition, cocaine $(30-100 \mu \mathrm{M})$ reduced the size of evoked EPSPs recorded in whole-cell current clamp without affecting the membrane potential (not shown) or input resistance of the cells (Fig. 1C, $n=7$ ). These results (Fig. 1) suggest that cocaine depresses excitatory synaptic transmission in the NAc by means of a specific mechanism that is independent of both local anesthetic effects and effects on postsynaptic conductances.
Similar results were obtained for amphetamine (Fig. 2A,B), which also increases extracellular DA levels (Seiden et al., 1993). Amphetamine $(10 \mu \mathrm{M})$ reversibly depressed the synaptic response but had no effect on action potential generation (Fig. $2 A)(n=8)$. Moreover, neither the membrane potential nor the input resistance of NAc cells was influenced by a concentration of amphetamine $(10 \mu \mathrm{M})$ that caused a substantial decrease in the EPSP (Fig. $2 B)(n=8)$. If cocaine and amphetamine depress synaptic transmission by increasing extracellular DA (Kuhar et al., 1991; Seiden et al., 1993), then DA should mimic the effects of these psychostimulants. Indeed, DA (75 $\mu \mathrm{M})$ depressed excitatory synaptic transmission without affecting N1 amplitude (Fig. $2 C)(n=21)$ and without affecting the membrane potential or input resistance of postsynaptic cells (Fig. $2 D)(n=8)$. Thus, cocaine, amphetamine, and DA all affect excitatory synaptic transmission in a similar fashion in the NAc, with the exception that the reversal of the amphetamine effect after wash-out of the drug is prolonged (40-60 min) compared with the time course of DA recovery $(10-20$ min) (Fig. 2). This prolonged time course may be a consequence of the reversal of the vesicular DA transporter caused by the intracellular action of amphetamine, which is taken up into dopaminergic terminals (Sulzer et al., 1995).

\section{A presynaptic mechanism is responsible for the depressant effects of amphetamine and DA}

The mechanism of psychostimulant- and DA-induced depressant effects on excitatory synaptic transmission may involve a decrease in presynaptic neurotransmitter release, a decreased postsynaptic sensitivity to the neurotransmitter, or both mechanisms acting in concert. To determine which of these mechanisms is responsible, we used whole-cell voltage clamp $\left(V_{\mathrm{h}}=-80 \mathrm{mV}\right)$ to record spontaneous mEPSCs in the presence of TTX $(1.5 \mu \mathrm{M})$. A decrease in the frequency of spontaneous events recorded in these conditions is classically attributed to a reduction in the probability of neurotransmitter release or in the number of quanta available 
Figure 2. Amphetamine and DA reduce evoked synaptic responses. $A$, A typical field recording in which $10 \mu \mathrm{M}$ amphetamine reduced the synaptic response (N2) without affecting the nonsynaptic potential $(N 1)$. $B$, When $10 \mu \mathrm{M}$ amphetamine was applied to a cell in whole-cell current clamp, the initial slope of the EPSP was reduced, whereas the input resistance $(-0.03 \mathrm{nA}$ current injection) was unchanged. $C$, A representative field experiment in which $75 \mu \mathrm{M}$ DA reduced the synaptic polential (N2) but did not change the nonsynaptic potential $(N 1)$. $D$, Application of $75 \mu \mathrm{M}$ DA to a currentclamped cell reduced the initial slope of the EPSP without affecting the input resistance $(-0.03 \mathrm{nA}$ current injection).
A
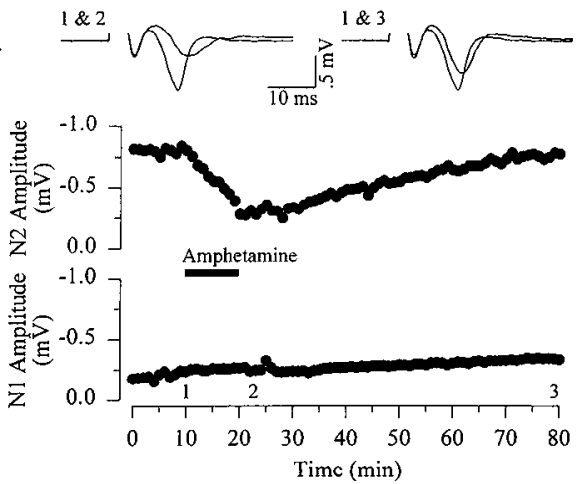

B

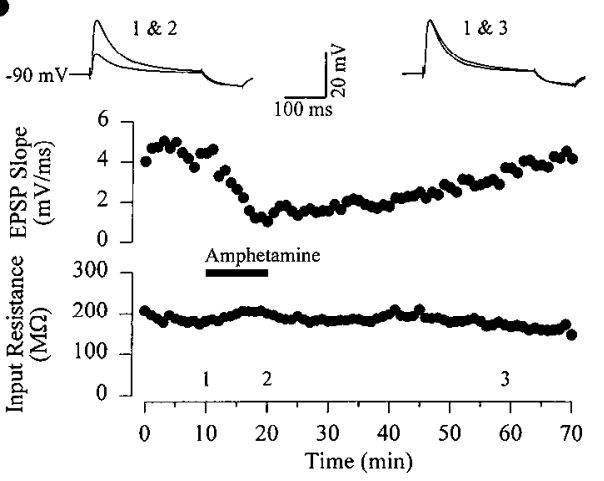

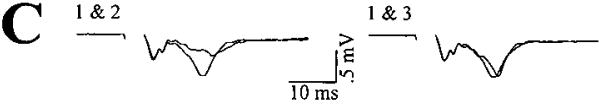
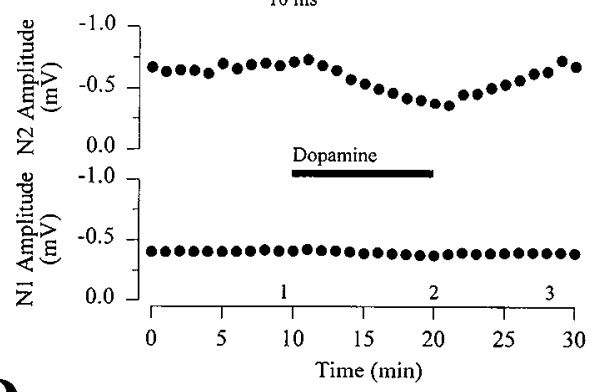

D
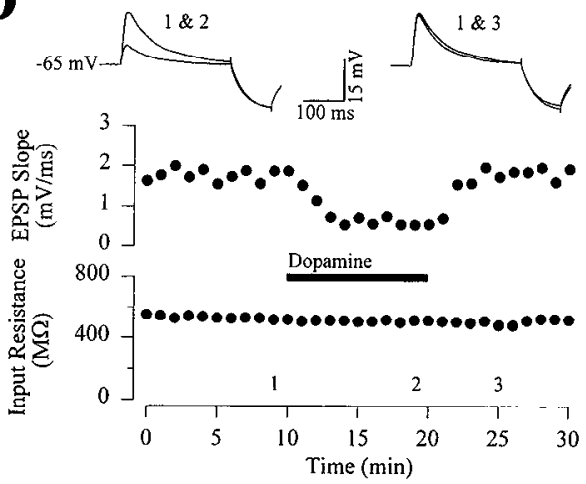

for release, whereas a decrease in the amplitude of these events normally indicates a reduction in the postsynaptic sensitivity to the released quanta (Katz, 1966). All recordings were initially made in the absence of TTX; TTX was then applicd, and complete abolition of evoked EPSCs was observed before the experiments summarized in Figures 3 and 4 were begun. The frequency of mEPSCs in NAc cells was quite high, often 10-15 $\mathrm{Hz}$, and the range of amplitudes was large (4-70 pA). To confirm that the recorded events were true mEPSCs arising from glutamate receptor activation, CNQX was applied (10 $\mu \mathrm{M})$ at the end of six experiments, and in each of these cases mEPSCs were blocked (Fig. $4 A$, far right). Because the effect of amphetamine on synaptic transmission was more robust than that of cocaine, we focused on the actions of amphetamine for the remainder of the study.

A typical experiment in which the effect of amphetamine $(10 \mu \mathrm{M})$ on mEPSC frequency and amplitude was examined is shown in Figure $3 A-G$. Representative consecutive current traces taken before (1), during (2), and after (3) amphetamine application (Fig. $3 A$ ) demonstrate that mEPSC frcquency, but not amplitude, was reversibly reduced by the presence of amphetamine. This result is summarized in Figure $3, B$ and $C$, which shows that mEPSC amplitude was unchanged throughout the entire course of the experiment (Fig. $3 C$ ), whereas amphetamine reduced mEPSC frequency with a time course of recovery similar to that observed for evoked responses (Fig. $3 B$ ). The distribution of mEPSC amplitudes was unaffected by amphetamine (Fig. $3 E, G$ ), whereas the distribution of the time intervals between successive mEPSCs was shifted toward longer intervals after application of amphetamine (Fig. 3D,F). These experiments were repeated in six cells in which mEPSC frequency was reduced to $57 \pm 2 \%$ of the baseline value $(p<0.05)$ (Fig. $3 H)$, whereas mEPSC amplitude remained at $95 \pm 3 \%$ of baseline $(p>0.1)$ (Fig. $3 I$ ).

Similar results were obtained when the effects of DA on mEPSCs were examined (Fig. 4). Representative consecutive current traces from a typical cell (Fig. $4 A$ ) demonstrate that mEPSC frequency, but not amplitude, was reversibly depressed by the application of DA $(100 \mu \mathrm{M})$ (Fig. $4 B, C)$. As was the case for amphetamine, DA did not cause a shift in the distribution of mEPSC amplitudes (Fig. $4 E, G$ ) but did cause a shift toward longer intervals between consecutive mEPSCs (Fig. 4D,F). Similar results were observed in 15 cells in which DA application resulted in an average reduction in $\mathrm{mEPSC}$ frequency to $61 \pm 4 \%$ of baseline values $(p<0.001)$ (Fig. $4 H$ ), whereas mEPSC amplitude in DA was $100 \pm 3 \%$ of baseline $(p>0.05)$ (Fig. 4I). Thus, both DA and amphetamine reduce mEPSC frequency without affecting mEPSC amplitude, suggesting that they both depress excitatory synaptic transmission via a presynaptic mechanism.

Although the reduction in mEPSC frequency strongly suggests that DA and psychostimulants act presynaptically, the exact identity of the excitatory synapses that contribute to the mEPSC distributions is unknown. The NAc receives excitatory afferents from many different brain regions in addition to the prelimbic cortex (Pennartz et al., 1994), and it is therefore possible that terminals not of cortical origin were mainly responsible for the observed amphetamine- and DA-induced reduction in mEPSC frequency. To examine further whether DA reduces corticoaccumbens excitatory transmission via a presynaptic mechanism, we tested the effect of DA on paired-pulse facilitation (PPF), a presynaptic phenomenon, the magnitude of which correlates inversely with the probability of neurotransmitter release (Zucker, 1989; Manabe et al., 1993). A pair of synaptic responses was elicited with an interstimulus interval of 50-100 msec, and the magnitude of increase of the second response relative to the first one was monitored continuously during the experiment. To obviate any effect of nonlinear summation on the magnitude of PPF (Martin, 1955), experiments were performed in voltage clamp. Figure 5 demonstrates that an increase in the PPF ratio occurs simultaneously with the reduction in EPSC amplitude induced by 


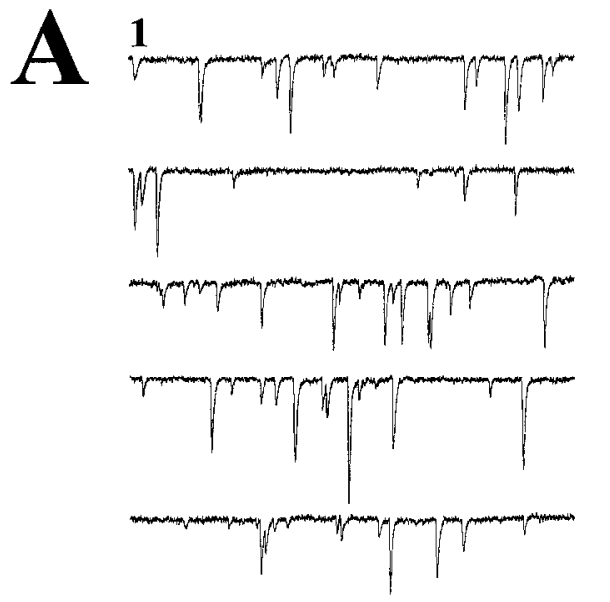

B

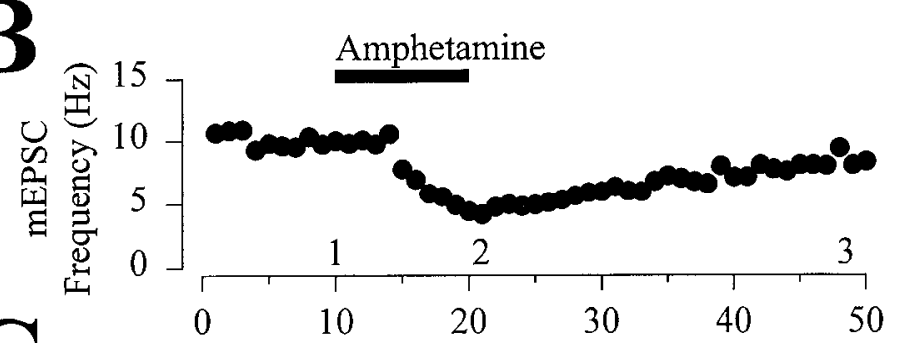

C

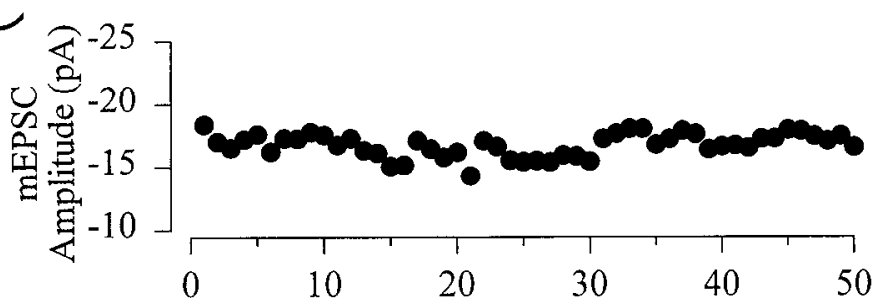

Time (min)

F
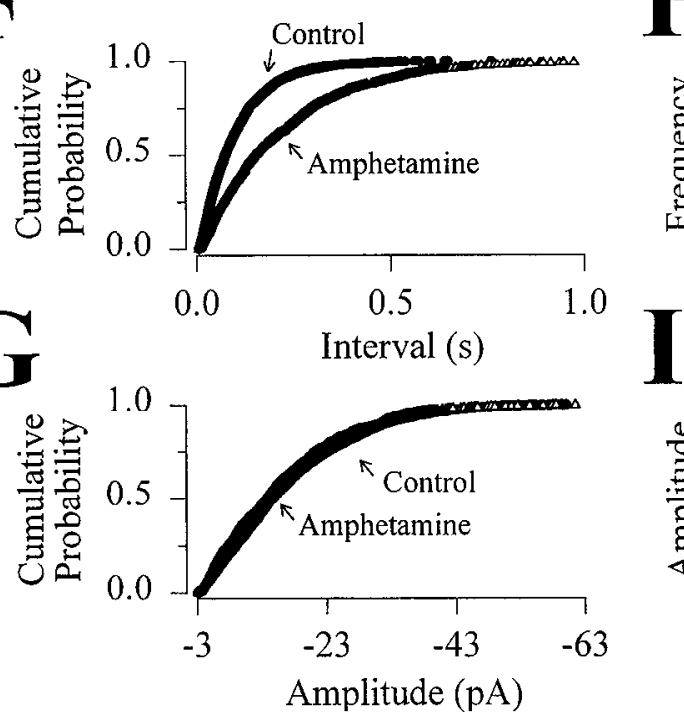

2

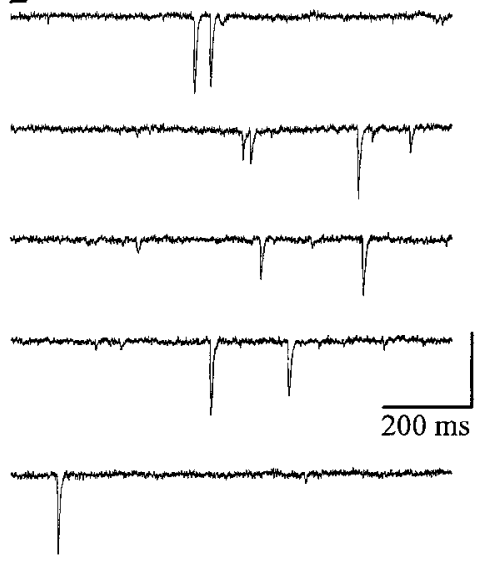

3

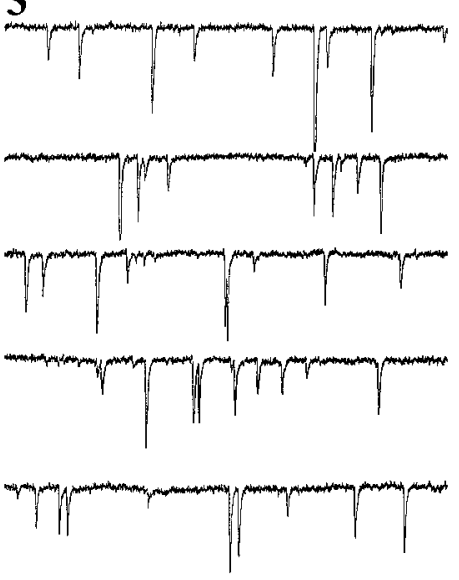

D
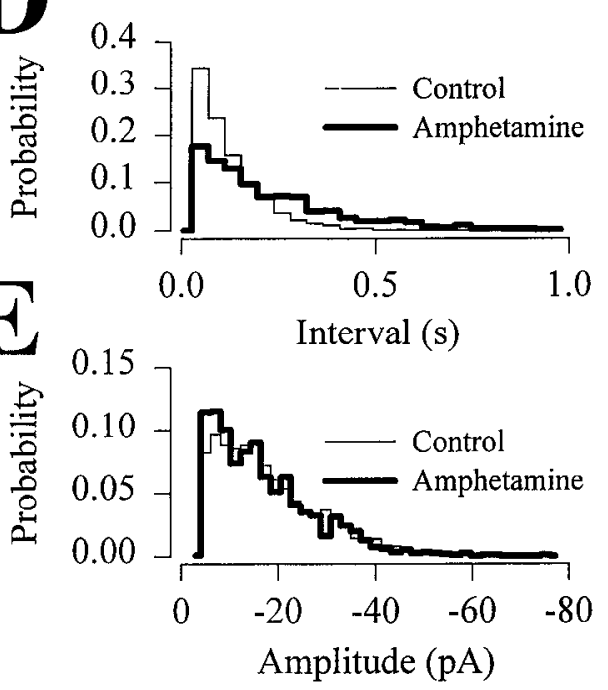

Amphetamine
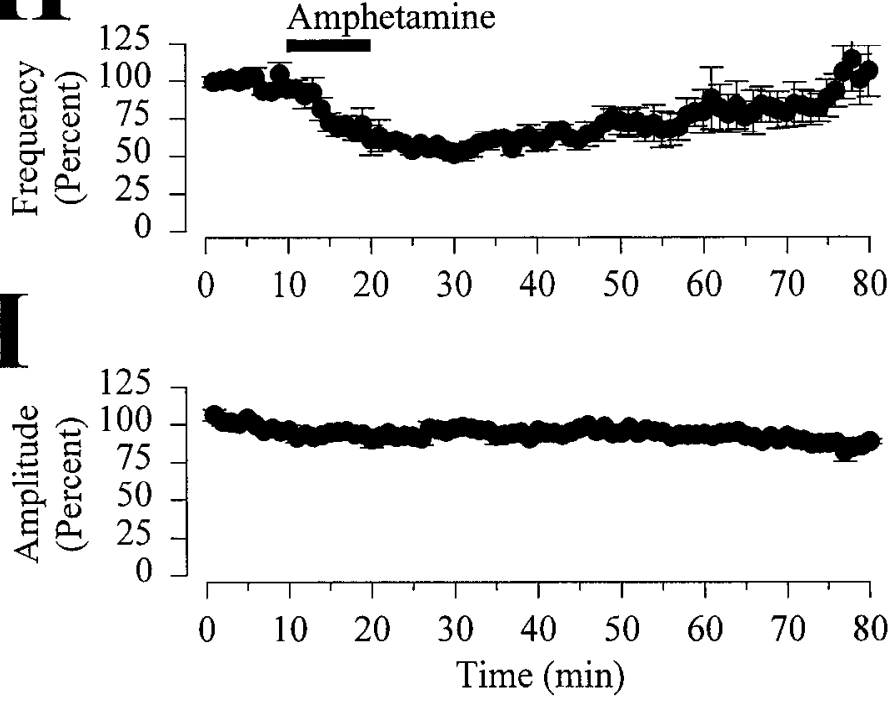

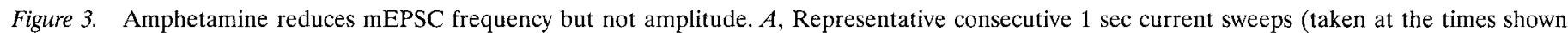

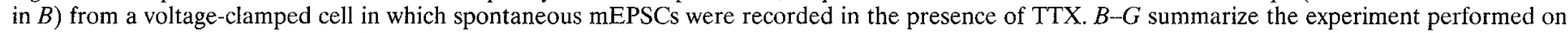

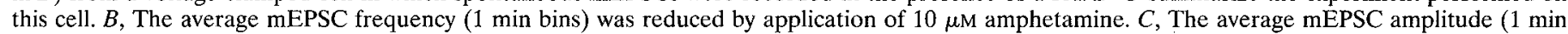

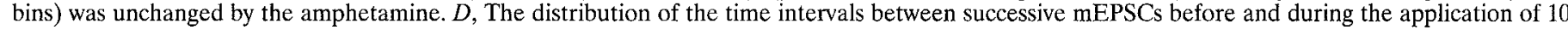

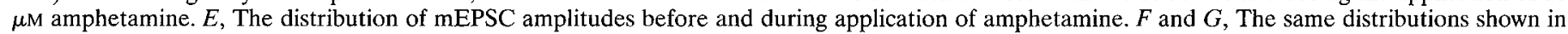

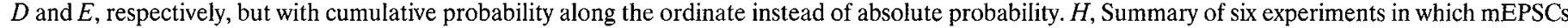

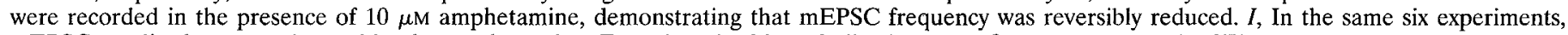
mEPSC amplitude was unchanged by the amphetamine. Error bars in this and all subsequent figures represent the SEM. 


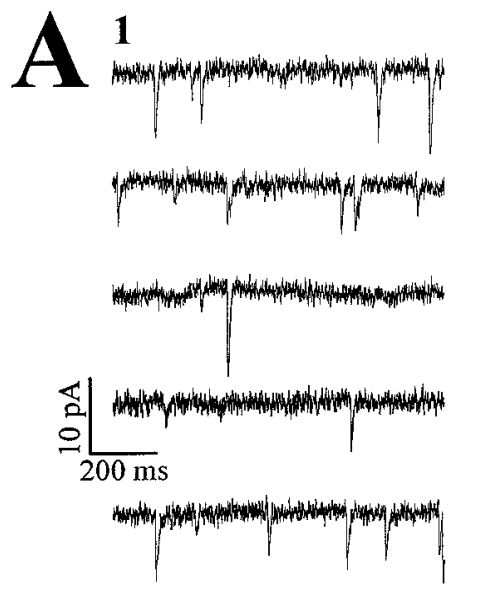

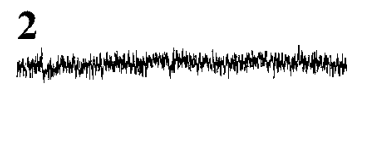

3

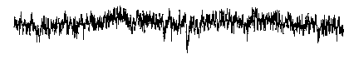

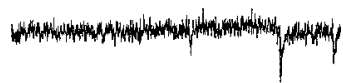

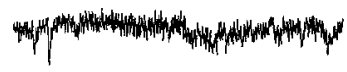

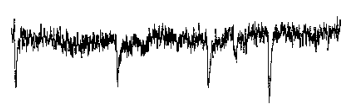

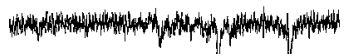

Why<smiles>CC(C)N[C@@H](C)C(C)C</smiles>

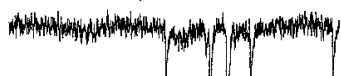

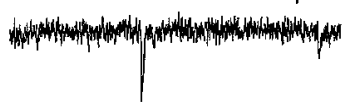

CNQX

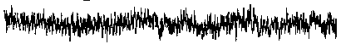

Nay

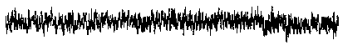

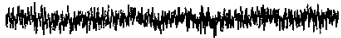

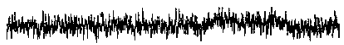

B
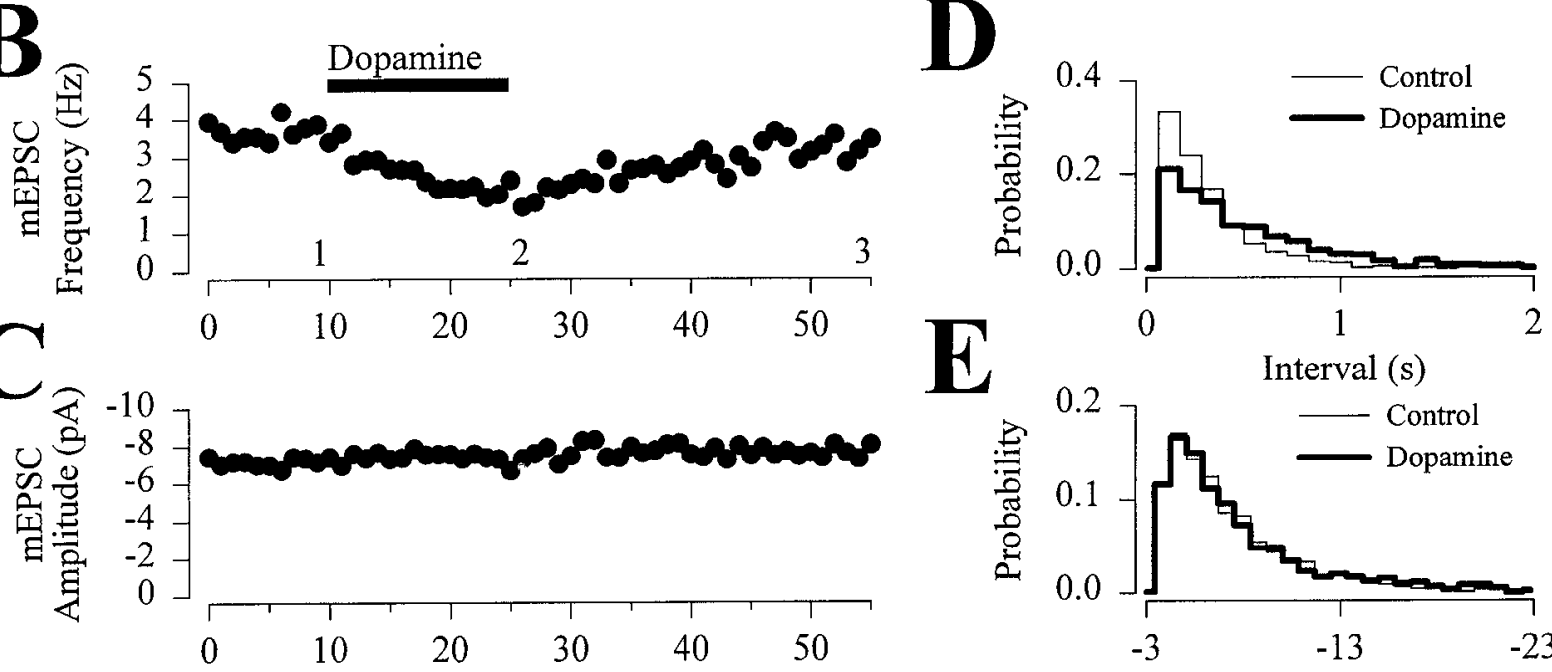

竞
0
0
0
0
0

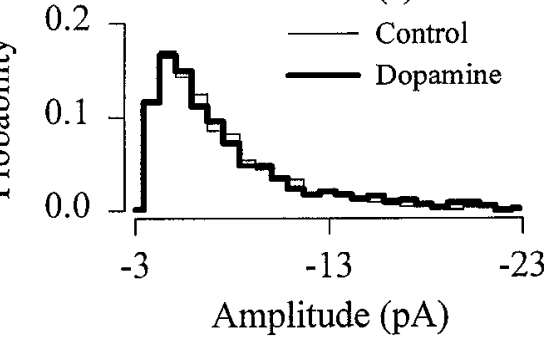

1

Time (min)

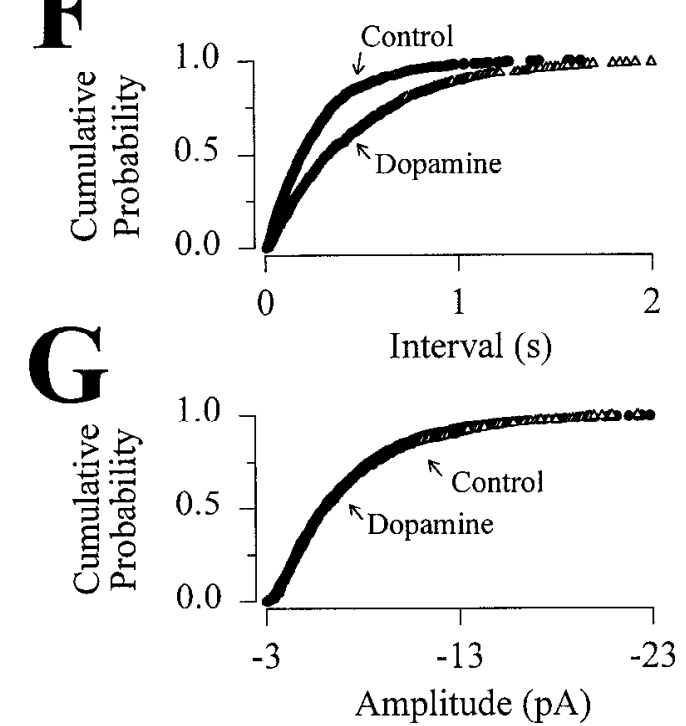

$\mathbf{H}$

Amplitude (pA)

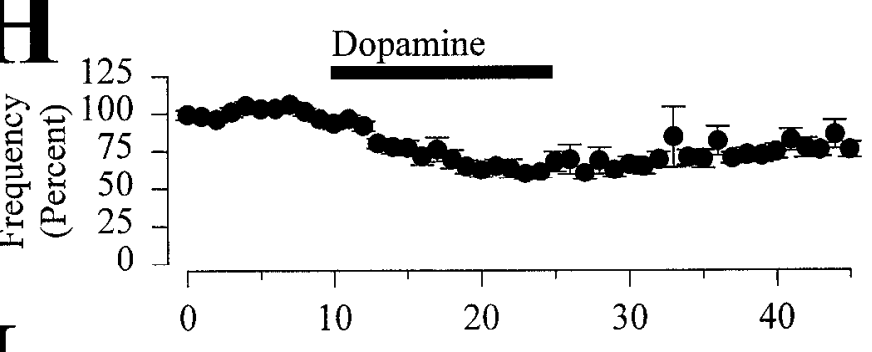

I

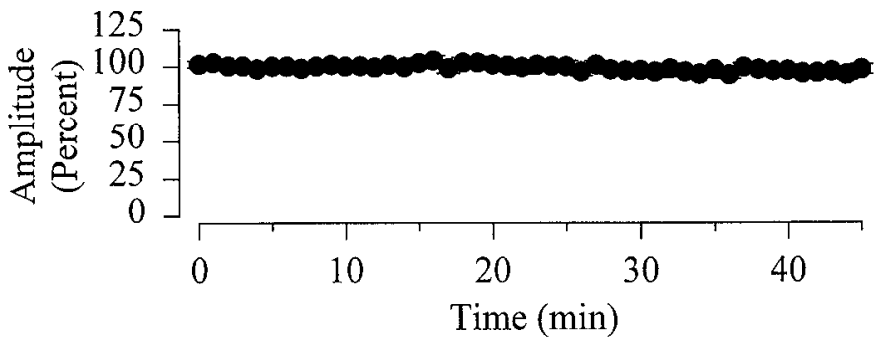

Figure 4. DA reduces mEPSC frequency but not amplitude. $A$, Representative consecutive 1 sec current sweeps (taken at the times shown in $B$ ) from a voltage-clamped cell in which spontaneous mEPSCs were recorded in the presence of TTX. The last set of sweeps was taken at the end of the experiment, after application of $10 \mu \mathrm{M}$ CNQX. $B-G$ summarize the experiment performed on this cell. $B$, The average mEPSC frequency (1 min bins) was reduced by application of $100 \mu \mathrm{M} \mathrm{DA}$. $C$, The average mEPSC amplitude ( 1 min bins) was unchanged by the DA. $D$, The distribution of the time intervals between successive mEPSCs before and during the application of $100 \mu \mathrm{M} \mathrm{DA}$. $E$, The distribution of mEPSC amplitudes before and during application of DA. $F$ and $G$, The same distributions shown in $D$ and $F$, respectively, but with cumulative prohahility along the ordinate instead of absolute probability. $H$, Summary of 15 experiments in which mEPSCs were recorded during application of $100 \mu \mathrm{M}$ DA, demonstrating that mEPSC frequency was reversibly reduced. $I$, In the same 15 experiments, mEPSC amplitude was unchanged by the DA. 
A

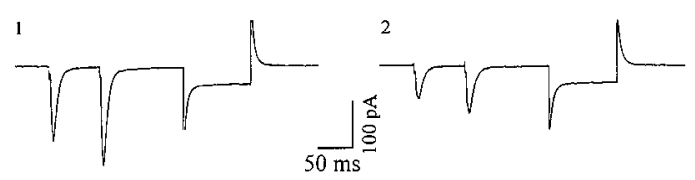<smiles>C=CC(C)CC(C)CCC</smiles>

B
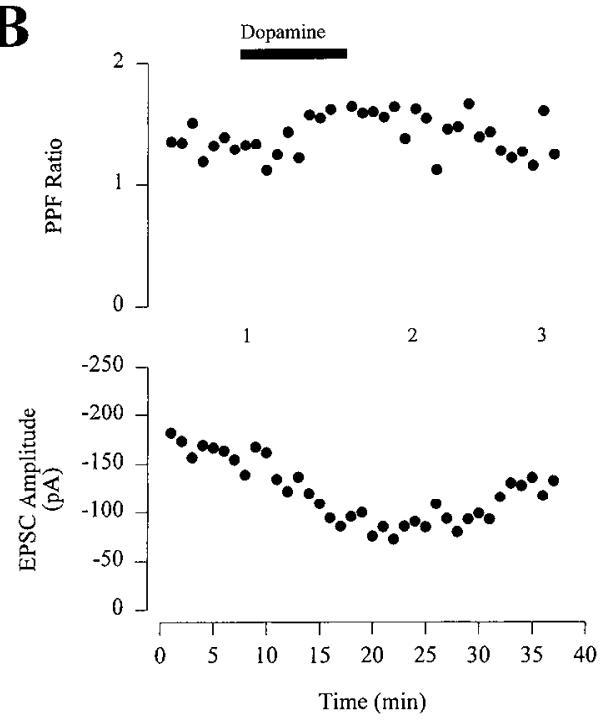

C
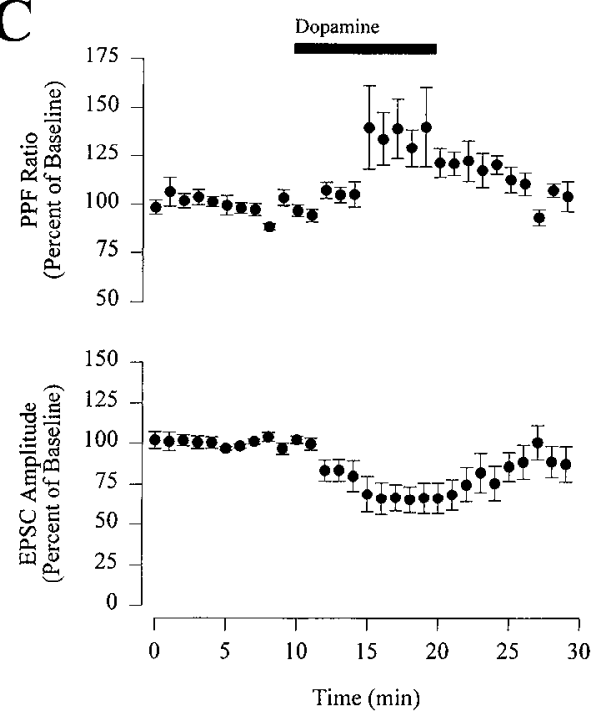

Figure 5. DA increases PPF. $A$, Representative current traces from the voltageclamped cell shown in $B$. Two stimuli were administered with an interpulse interval of $75 \mathrm{msec}$. The current deflection heginning $400 \mathrm{msec}$ after the first stimulus was the result of a $-10 \mathrm{mV}$ voltage pulse. For clarity, capacitive transients were truncated. $B$, The ratio of the amplitude of the second EPSC to that of the first increases with the application of $75 \mu \mathrm{M}$ DA (top), which simultaneously reduces the amplitude of the first EPSC (bottom). $C$, Summary $(n=8)$ of voltage-clamp experiments similar to the one shown in $B$.
DA $(75 \mu \mathrm{M})$. DA increased the PPF ratio to an average of $129 \pm$ $7 \%$ of the baseline PPF ratio $(n=8 ; p \leq 0.024$, Wilcoxon rank sum test) (Fig. 5C, top), an increase that accompanied a decrease in the amplitude of the first pulse to $71 \pm 10 \%$ of the baseline amplitude ( $n=8 ; p \leq 0.054$, Wilcoxon rank sum test) (Fig. $5 C$, bottom.). The results of these experiments suggest that psychostimulants and DA act at cortico-accumbens synapses to reduce transmitter release, thereby decreasing the efficacy of excitatory transmission between the cortex and the NAc.

\section{Amphetamine and DA depress excitatory synaptic transmission via a DA receptor with D1-like properties}

DA receptors can be subdivided into two pharmacologically and biochemically distinct classes (Civelli et al., 1993; Sibley, 1995),
A
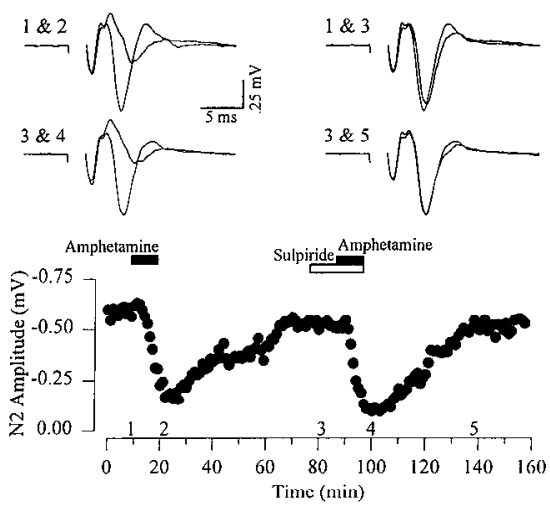

B

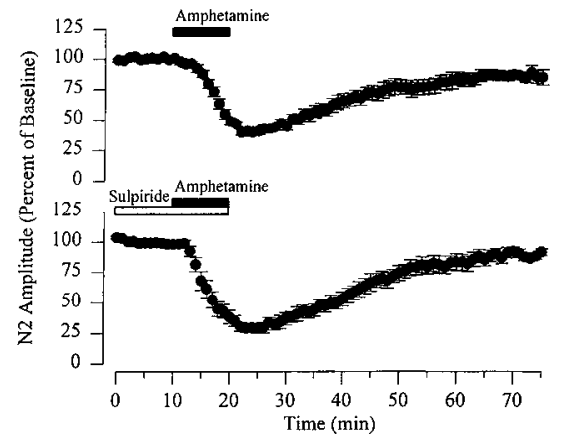

D
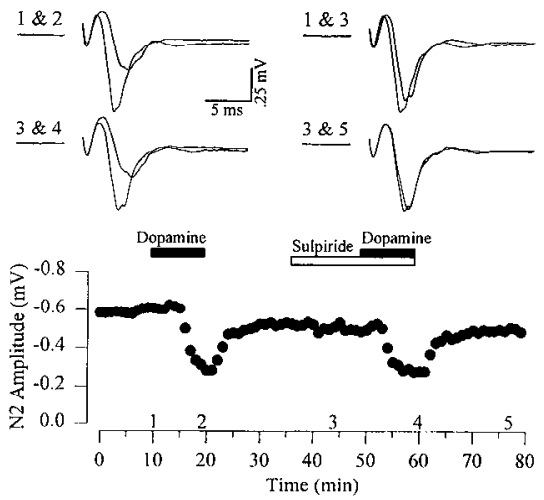

$\mathbf{E}$

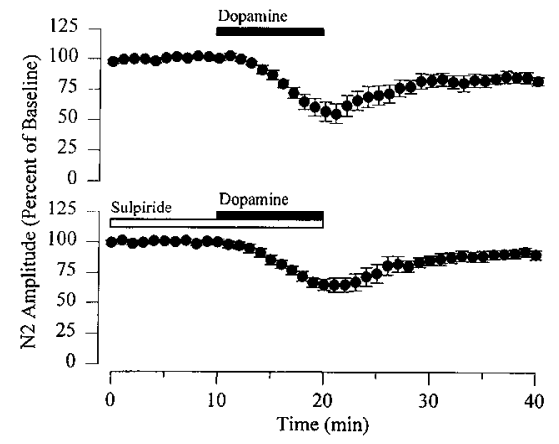

Figure 6. The D2 antagonist sulpiride does not affect the synaptic depression resulting from application of amphetamine or DA. $A$, A typical field recording experiment in which $10 \mu \mathrm{M}$ amphetamine was first applied in the absence of sulpiride and then in the presence of 10 $\mu \mathrm{M}$ sulpiride. $B$, Summary of eight field experiments in which $10 \mu \mathrm{M}$ amphetamine was applied in the absence of sulpiride. $C$, In the same eight experiments, amphetamine $(10 \mu \mathrm{M})$ was again applied in the presence of $10 \mu \mathrm{M}$ sulpiride; the amphetamine-induced reduction in the synaptic response was not diminished by the sulpiride. $D$, A representative field recording in which $75 \mu \mathrm{M}$ DA was applied first in the absence and then in the presence of sulpiride (10 $\mu \mathrm{M}) . E$, Summary of eight experiments, demonstrating the effects of DA $(75 \mu \mathrm{M})$ in the absence of sulpiride. $F$, In 12 experiments ( 5 of which were performed in the same slices as those shown in $E$ and the remainder of which were interleaved with those shown in $E)$, DA $(75 \mu \mathrm{M})$ was applied in the presence of $10 \mu \mathrm{M}$ sulpiride; the sulpiride did not block the reduction of the synaptic response caused by DA. 
Figure 7. The D1 antagonist SCH 23390 inhibits the synaptic actions of amphetamine and DA. $A$, A representative current-clamp experiment in which 10 $\mu \mathrm{M}$ amphetamine was first applied in the presence of $2 \mu \mathrm{M} \mathrm{SCH} 23390$ and again after washout of the SCH23390. A current injection of $-0.03 \mathrm{nA}$ was used to elicit the voltage deflections after the FPSPs. $R$, Summary $(n=8)$ of experiments in which $10 \mu \mathrm{M}$ amphetamine was applied. $C$, Summary of experiments in which $10 \mu \mathrm{M}$ amphetamine was applied in the presence of $2 \mu \mathrm{M} \mathrm{SCH} 23390$, showing that $\mathrm{SCH} 23390$ blocked the effects of DA $(n=8,6$ of which were performed in the same cells as those shown in $B$ and the remainder of which were interleaved with them). $D$, A field recording experiment in which $75 \mu \mathrm{M}$ DA elicited a depression of the synaptic response that was sensitive to $\mathrm{SCH} 23390$ $(10 \mu \mathrm{M}) . E$, Summary $(n=14)$ of the effects of $75 \mu \mathrm{M} D A$ on the synaptic response. $F$, In the same 14 experiments as those shown in $E$, DA $(75 \mu \mathrm{M})$ was applied in the presence of $10 \mu \mathrm{M}$ SCH23390, which significantly reduced the effects of DA.
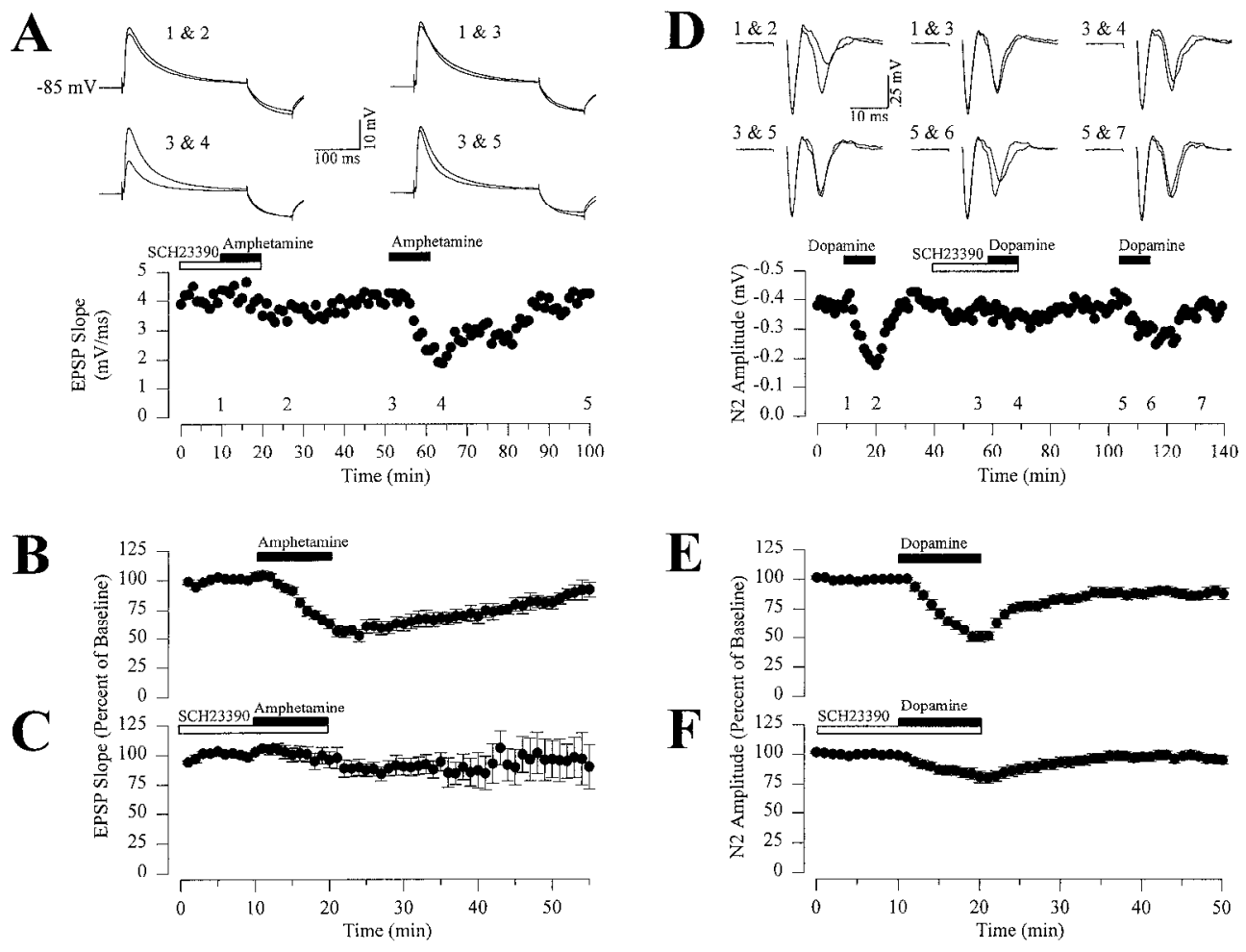

the D1-like (consisting of the cloned D1a and D1b receptors, also known as D1 and D5) and the D2-like receptors (consisting of D2, D3, and D4 receptors). Both D1-like and D2-like receptors are found in high concentrations in the NAc (Civelli et al., 1993), and thus either subtype could mediate the synaptic actions of DA. To begin the pharmacological characterization of the receptor responsible for the psychostimulant- and DA-induced depression of synaptic transmission, we examined the effects of specific D2 and D1 receptor antagonists (Figs. 6 and 7). Sulpiride $(10 \mu \mathrm{M})$, an antagonist specific for D2-like receptors (Civelli et al., 1993; Sibley, 1995), did not reduce the synaptic depression elicited by application of amphetamine $(10 \mu \mathrm{M}, p>0.9)$ (Fig. $6 A-C)$. This lack of effect of sulpiride was observed in eight slices that were exposed to both amphetamine alone $(10 \mu \mathrm{M}, 40 \pm 2 \%$ of baseline, $p<0.0001$ ) (Fig. 6B) and amphetamine in the presence of sulpiride (30 $\pm 4 \%$ of baseline) (Fig. $6 C$ ). Sulpiride also did not antagonize the depressant effect of DA (75 $\mu \mathrm{M}, p>0.1)$ (Fig. $6 D-F)$. In the absence of sulpiride, DA depressed the synaptic response to $58 \pm 8 \%$ of baseline ( $n=8, p<0.0001$ ) (Fig. $6 E$ ), whereas in the presence of sulpiride DA reduced the response to $65 \pm 5 \%$ of baseline $(n=12$, Fig. $6 F)$. Therefore, neither amphetamine nor DA seems to act through a D2-like receptor to produce depression of excitatory synaptic transmission.

In contrast, the D1 receptor antagonist SCH23390 (Civelli et al., 1993; Sibley, 1995) blocked the depressant action of both DA and amphetamine (Fig. 7). Figure $7 A$ shows an example of a cell in which amphetamine $(10 \mu \mathrm{M})$ had very little effect on the EPSP in the presence of SCH23390 $(2 \mu \mathrm{M})$, whereas it greatly reduced the EPSP after wash-out of the $\mathrm{SCH} 23390$. Similar results from a total of 10 cells are illustrated in Figure 7, $B$ and $C$. In the absence of SCH23390, amphetamine $(10 \mu \mathrm{M})$ reduced EPSPs to $57 \pm 4 \%$ of baseline ( $n=8, p<0.0001$ ), whereas in the presence of $2 \mu \mathrm{M}$ $\mathrm{SCH} 23390$, the EPSPs in amphetamine remained at $92 \pm 8 \%$ of baseline $(n=8)$. The effect of amphetamine was therefore significantly reduced by $\mathrm{SCH} 23390(p<0.001)$. As shown in the example in Figure $7 D, \mathrm{SCH} 23390$ antagonized the effects of DA as well. On average, DA $(75 \mu \mathrm{M})$ reduced the synaptic response to $51 \pm 4 \%$ of baseline when SCH23390 was not present $(n=14$, $p<0.0001$ ) (Fig. 7E), whereas in the same slices it reduced the response to only $81 \pm 5 \%$ of baseline in the presence of $\mathrm{SCH} 23390$, a significant reduction in the degree of depression caused by $\mathrm{DA}(p<0.002)$ (Fig. $7 F)$.

If psychostimulants and DA act through a D1-like receptor to depress synaptic transmission, then D1 but not D2 agonists should mimic the depressant actions of amphetamine, cocaine, and DA. 6,7-ADTN $(50 \mu \mathrm{M})$, a DA agonist that activates both D1-like and D2-like receptors, reduced the EPSP to $58 \pm 8 \%$ of baseline ( $n=4, p<0.02$ ) (Fig. $8 A$ ). In contrast, the D2-specific agonist quinpirole $(20 \mu \mathrm{M})$ did nol significantly depress EPSPs $(92 \perp 7 \%$ of baseline, $n=6, p>0.2$ ) (Fig. $8 B$ ). These results are consistent with the involvement of a D1-like receptor; however, the results obtained with D1 agonists were less clear. Neither the partial D1 agonist (+)-SKF38393 (30 $\mu \mathrm{M}, n=6)$ (Fig. $8 C$ ) nor the full D1 agonist (士)-SKF81297 (30 $\mu \mathrm{M}, n=11)$ (Fig. $8 D$ ) significantly reduced EPSPs (103 $\pm 5 \%$ of baseline, $p>0.5$, and $93 \pm 5 \%$ of baseline, $p>0.1$, respectively), despite the fact that these agonists were used at concentrations exceeding their $\mathrm{EC}_{50}$ values for activation of $\mathrm{D} 1$ receptors, as determined by c $\Lambda \mathrm{MP}$ assays in striatal tissue (Andersen and Jansen, 1990); however, $100 \mu \mathrm{M}$ $( \pm)$-SKF38393 did reduce synaptic responses to $77 \pm 3 \%$ of baseline $(n=6, p<0.01$ ) (Fig. $9 A$ ), and this effect was significantly antagonized $(p<0.02)$ by SCH23390 $(10 \mu \mathrm{M}, 94 \pm 10 \%$ of baseline, $n=4$ ) (Fig. $9 B$ ).

These pharmacological results are most consistent with the hypothesis that activation of a D1-like receptor is responsible for the depression of synaptic transmission caused by psychostimu- 

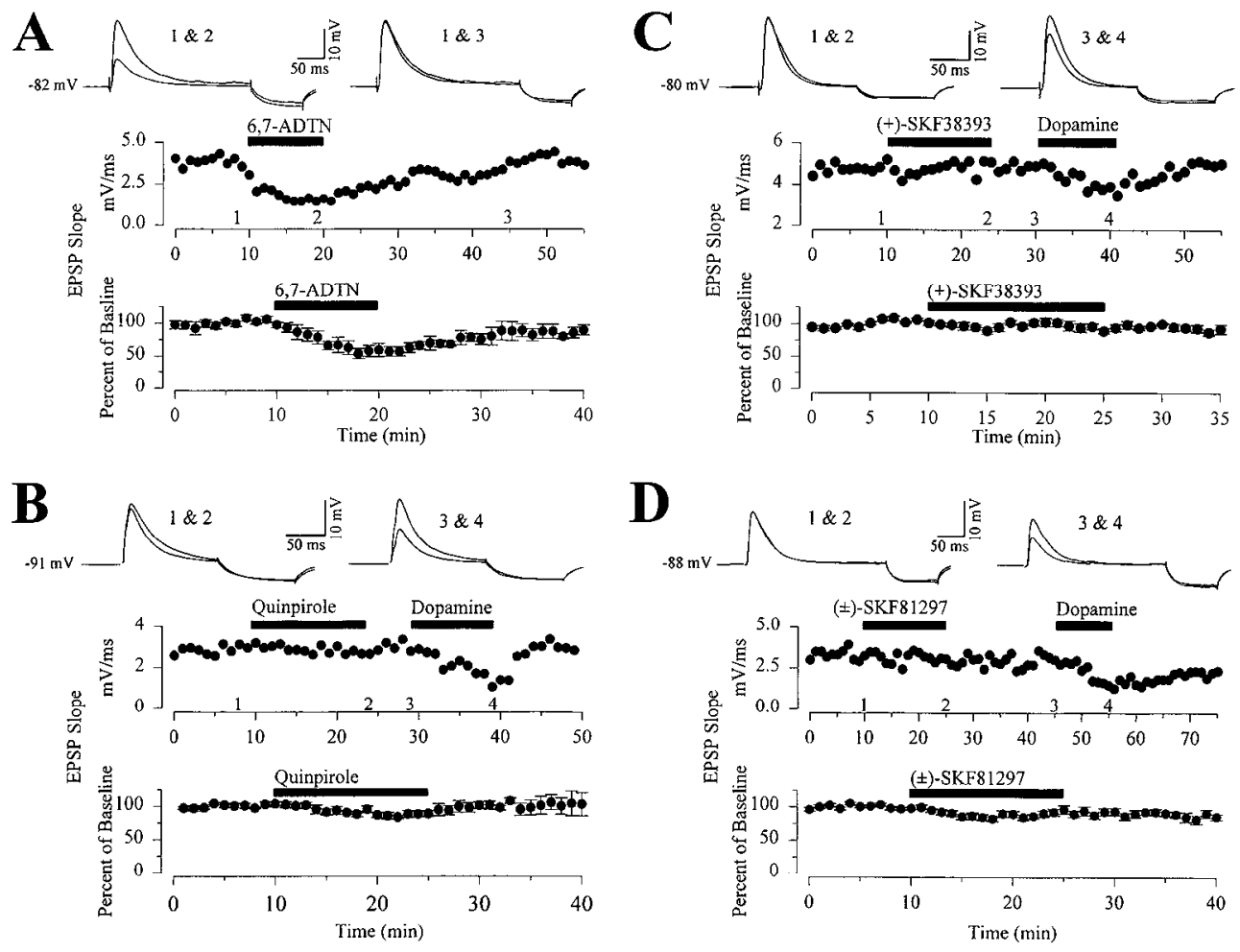

Figure 8. A broad-spectrum DA agonist reduces the EPSP, whereas specific $\mathrm{D} 1$ and $\mathrm{D} 2$ agonists do not. $A$, The DA agonist $6,7-\mathrm{ADTN}(50 \mu \mathrm{M})$ reversibly reduced the initial slope of the EPSP, as shown by an example (top) and a summary of four experiments (bottom). $B, \mathrm{~A}$ representative experiment (top) demonstrates that the $\mathrm{D} 2$ agonist quinpirole ( 20 $\mu \mathrm{M})$ had no effect on the EPSP initial slope, whereas $75 \mu \mathrm{M}$ DA reduced the EPSP; the lack of effect of quinpirole is summarized in the bottom graph $(n=6$ cells). $C$, The partial D1 agonist (+)SKF38393 $(30 \mu \mathrm{M})$ did not reduce the EPSP initial slope in a typical cell, whereas a reduction could be obtained by $75 \mu \mathrm{M}$ DA (top); the bottom graph summarizes the effects of $(+)$-SKF38393 $(n=6$ cells $) . D$, An example demonstrat ing that the full D1 agonist ( \pm )SKF81297 $(30 \mu \mathrm{M})$ did not reduce the initial slope of the EPSP, whereas $75 \mu \mathrm{m}$ DA did (top); the bottom graph summarizes the effects of $( \pm)$-SKF81297 $(n=$ 11). The current injection used to obtain the voltage deflections in all the cells depicted in this figure was $-0.03 \mathrm{nA}$.

lants and DA. Although the concentrations of Dl agonist required to observe the effect are high, there are reports of a neurochemical effect in striatal slices with a pharmacological profile very similar to that found here (Undie and Friedman, 1990, 1992; Undie et al., 1994) (see Discussion). To begin to test more directly the role of specific D1-like receptors, we next examined the effects of DA on cortico-accumbens synaptic transmission in slices prepared from mutant mice lacking D1a receptors ( $\mathrm{Xu}$ et al., 1994a,b). As illustrated in Figure 10, there was no difference in the depressant effects of DA in slices prepared from the mutant mice when compared with slices prepared from wild-type control mice $(p>0.9)$. DA $(75 \mu \mathrm{M})$ reduced the EPSP to $73 \pm 14 \%$ of baseline in the wild-type mice $(n=5, p<0.003$ ) (Fig. 10A,C) and to $73 \pm 6 \%$ of baseline in the mice lacking D1a receptors $(n=9)$ (Fig. 10B,C). Thus, D1a receptors are not essential for the DAinduced reduction in excitatory synaptic transmission in the NAc.

In the VTA, activation of DI-like receptors on the terminals of GABA-containing afferents facilitates evoked GABA release (Cameron and Williams, 1993). If DA has similar actions in the NAc, then its depressant effects on excitatory synaptic transmission conceivably could be indirect and attributable to a D1 receptor-mediated increase in extracellular GABA levels. This would result in activation of presynaptic $\mathrm{GABA}_{\mathrm{B}}$ receptors, which inhibit excitatory synaptic transmission in the NAc (Uchimura and North, 1991). To test whether such a mechanism accounts for the effects of DA on excitatory synaptic transmission, we applied DA $(75 \mu \mathrm{M})$ to six slices, first in the absence and then in the presence of the $\mathrm{GABA}_{\mathrm{B}}$ receptor antagonist CGP35348 $(500 \mu \mathrm{M})$. Responses were depressed by DA to the same extent whether or not the antagonist was present $(65 \pm 6 \%$ of baseline for control, $66 \pm$ $6 \%$ of baseline in the presence of CGP35348, $p>0.5$ ), indicating that $\mathrm{GABA}_{\mathrm{B}}$ receptors are not involved in the observed effects of DA.

Because psychostimulants can increase the extracellular levels of monoamines other than DA (Cunningham et al., 1992; Seiden et al., 1993) and DA can act on non-DA receptors (Malenka and Nicoll, 1986; Goldberg, 1972), we were concerned that non-DA receptors may have contributed to the observed effects of psychostimulants and DA agonists. We therefore examined the effects of two monoamine neurotransmitters that might be expected to contribute to the actions of psychostimulants. Norepinephrine $(100 \mu \mathrm{M})$ reduced synaptic responses to $73 \pm 3 \%$ of baseline ( $n=11, p<0.0001$ ), an effect that was abolished by the $\alpha$-adrenergic antagonist phentolanine $(10 \mu \mathrm{M})(98 \pm 2 \%$ of baseline, $n=5, p>0.05$, Student Newman-Keuls test) but not affected by the $\beta$-adrenergic antagonist propranolol $(10 \mu \mathrm{M})(73 \pm$ $4 \%$ of baseline, $n=7, p<0.05$, Student Newman-Keuls test); however, phentolamine $(10 \mu \mathrm{M})$ did not antagonize the reduction in synaptic responses caused by amphetamine $(10 \mu \mathrm{M})(51 \pm 7 \%$ of baseline for amphetamine alone, $n=7 ; 63 \pm 10 \%$ of baseline for amphetamine in the presence of phentolamine, $n=7 ; p>0.05$ for the effect of phentolamine on amphetamine). Serotonin (2 $\mu \mathrm{M})$ also caused a decrease in synaptic responses $(81 \pm 7 \%$ of baseline, $n=7$ ), but this decrease was not reduced by SCH 23390 $(10 \mu \mathrm{M})(50 \pm 8 \%$ of baseline, $n=5)$ at the concentration that antagonized the effects of amphetamine and DA (Fig. 7). It is therefore unlikely that activation of adrenergic or serotonergic receptors are important in mediating the psychostimulantinduced depression of synaptic transmission in the NAc.

As a final test of the importance of DA in mediating the effects of the psychostimulants, we examined the consequences of lesioning the dopaminergic pathway from the VTA into the NAc by injecting 6-OHDA into the medial forebrain bundle of one hemisphere. Such lesions cause dopaminergic axons and terminals to degenerate within $4 \mathrm{~d}$ after the injection (Ungerstedt, 1971). If amphetamine causes a synaptic depression by releasing DA from dopaminergic terminals, then eliminating these terminals should block the synaptic actions of amphet- 

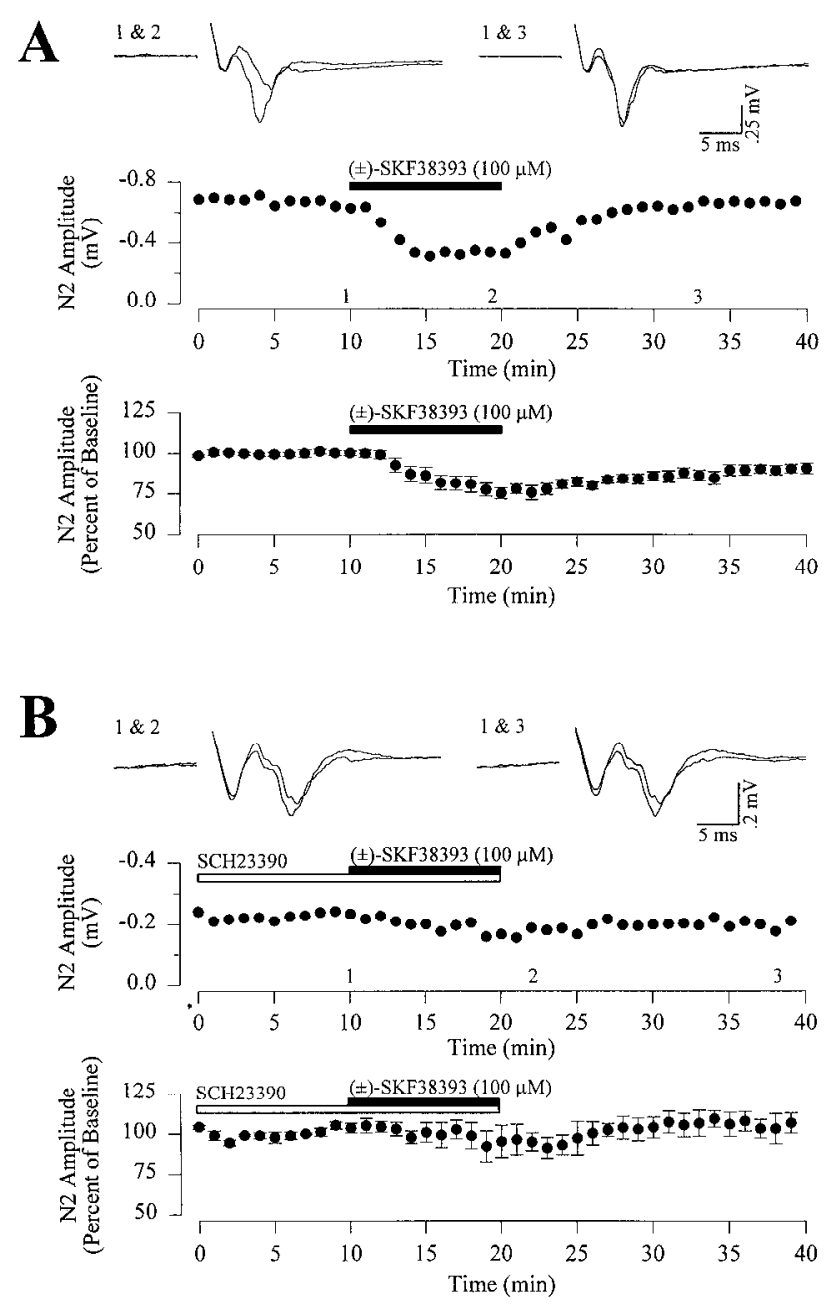

Figure 9. A higher concentration of a D1 agonist reduces the synaptic response, and this effect is antagonized by $\mathrm{SCH} 23390 . A$, As shown in an example (top) and a summary of six experiments (bottom), $100 \mu \mathrm{M}( \pm)$ SKF38393 depressed synaptic responses. $B$, SCH23390 (10 $\mu \mathrm{M})$ blocked the reduction in the synaptic response caused by $100 \mu \mathrm{M}( \pm)$-SKF38393, as shown in an example (top) and a summary (bottom) of four experiments (each of which was performed in the same slices as those summarized in $A$ ).

amine. Before preparing slices from 6-OHDA-lesioned animals, we examined the apomorphine-induced increase in rotation behavior, a standard behavioral assay that tests for the effectiveness of a lesion in the nigro-striatal pathway (Hefti et al., 1979). All three of the 6-OHDA-treated animals exhibited a strong tendency to rotate to the side opposite the lesion, with the average turning rate being 3.1 turns/min for the $5 \mathrm{~min}$ beginning $15 \mathrm{~min}$ after the injection of apomorphine $(1 \mathrm{mg} / \mathrm{kg}$, i.p.). Unlesioned control rats treated with the same dose of apomorphine did not rotate in either direction $(n=2)$. These results indicate that the 6-OHDA injections were effective in lesioning a significant proportion of DA-containing fibers (Hefti et al., 1979). Figure 11, $A$ and $B$, illustrates that the effect of amphetamine on synaptic transmission could be reduced drastically in slices prepared from the lesioned hemisphere when compared with its effects in slices prepared from the contralateral, control hemisphere. On average, amphetamine $(5-10 \mu \mathrm{M})$ caused a significantly greater reduction $(p<$ $0.03)$ in the synaptic responses in slices prepared from unle-
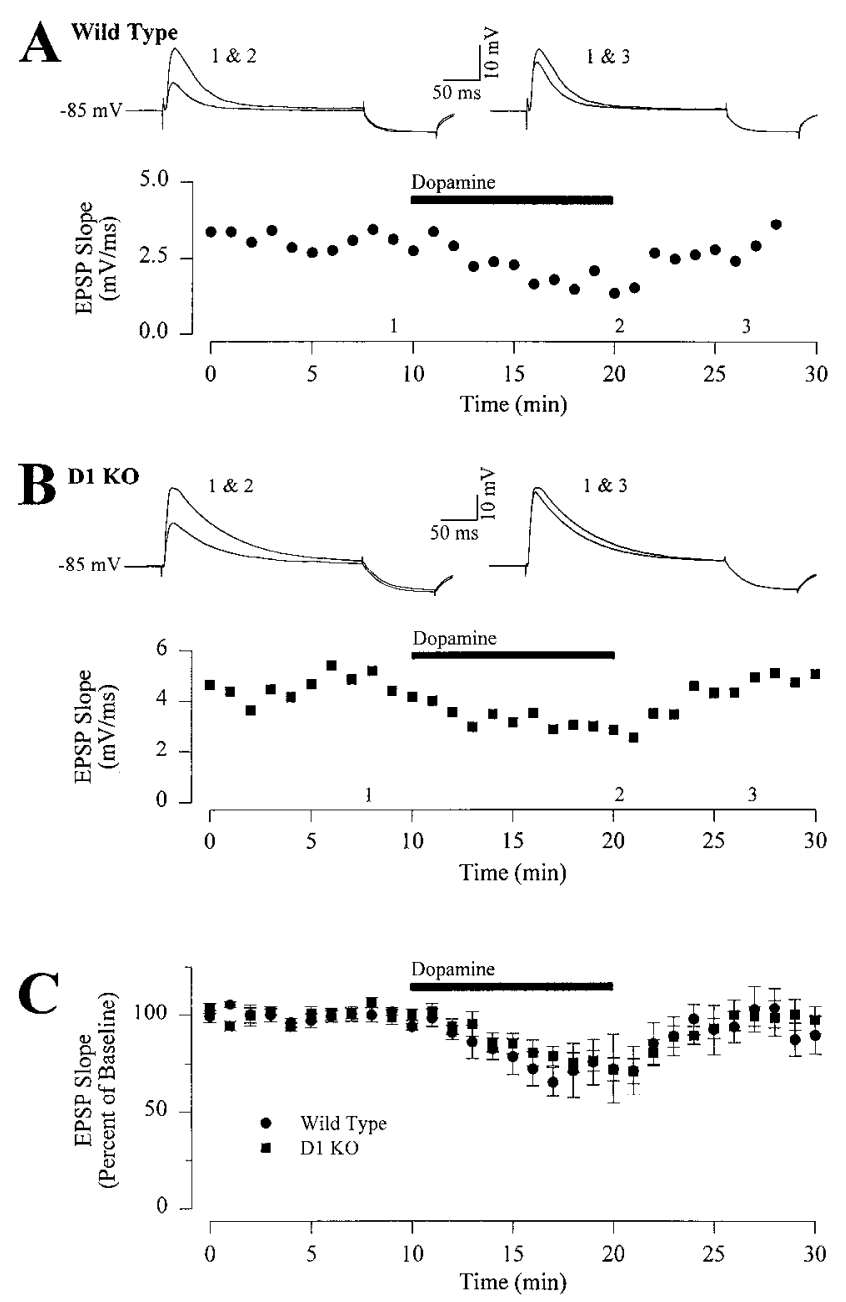

Figure 10. DA reduces the EPSP to the same extent in slices taken from mutant mice lacking D1a receptors and in slices taken from control mice. $A$, In a cell from a wild-type control mouse, $75 \mu \mathrm{M}$ DA reduced the initial slope of the EPSP. $B$, DA $(75 \mu \mathrm{M})$ had similar effects in a cell from a D1a mutant mouse. $C$, A summary of current-clamp recordings in cells from wild-type mice $(n=5)$ and D1a knock-out mice $(n=9)$, demonstrating that the reduction in the EPSP initial slope was nearly identical in mutant and control mice. The current injections used to obtain the voltage deflections after the EPSPs were $-0.03 \mathrm{nA}$ in the traces shown in this figure.

sioned hemispheres $(27 \pm 12 \%$ of baseline synaptic responses, $n=6$ ) (Fig. 11C) than in slices prepared from 6-OHDAlesioned hemispheres ( $58 \pm 10 \%$ of baseline, $n=8$ ) (Fig. 11C). These results provide additional evidence indicating that the effects of amphetamine on cortico-accumbens synaptic transmission are in large part attributable to the release of DA from DA-containing terminals.

\section{DISCUSSION}

The NAc is an important site of action for drugs of abuse, including the psychostimulants amphetamine and cocaine (Koob and Bloom, 1988; Nestler, 1992). The behavioral and addictive properties of these drugs are thought to be attributable in large part to their interactions with DA-containing nerve terminals (Robinson and Berridge, 1993; Kalivas and Stewart, 1991). There is also accumulating evidence from behavioral studies that glutamate receptors are important in mediating the behavioral effects of psychostimulants (Pul- 


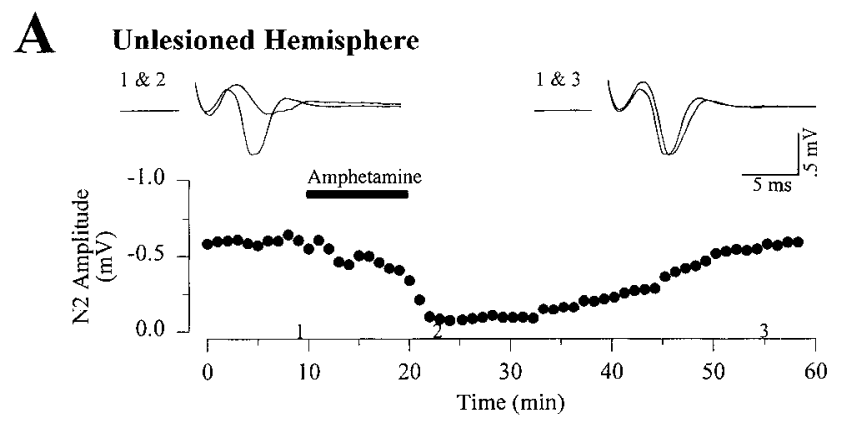

B
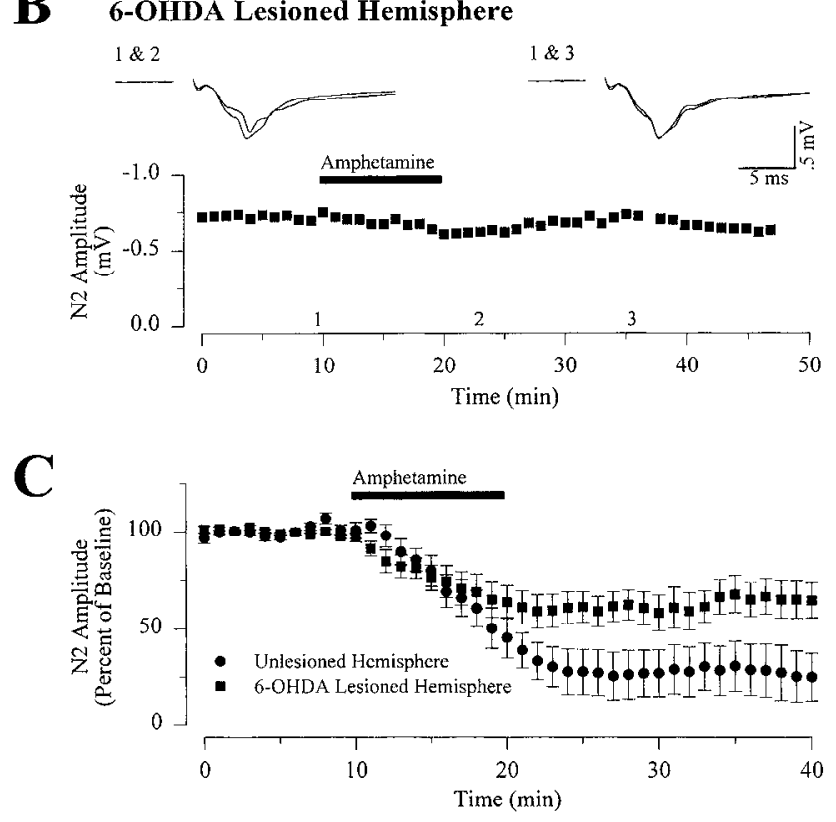

Figure 11. Unilateral lesions of dopaminergic afferents to the nucleus accumbens diminish the synaptic actions of amphetamine. $A$, In a slice taken from the unlesioned hemisphere, $5 \mu \mathrm{M}$ amphetamine caused a large reduction in the synaptic response. $B$, In a slice taken from the same rat, but from the hemisphere that had sustained a 6-OHDA lesion in the medial forebrain bundle, $5 \mu \mathrm{M}$ amphetamine had little effect. $C$, Summary of experiments in which amphetamine was applied to slices from the unlesioned hemispheres (5 $\mu \mathrm{M}, n=3 ; 10 \mu \mathrm{M}, n=3$ ) and 6-OHDA lesioned hemispheres ( $5 \mu \mathrm{M}, n=4 ; 10 \mu \mathrm{M}, n=4)$ of three rats.

virenti et al., 1991; Karler and Calder, 1992; Kelley and Throne, 1992; Wolf and Jeziorski, 1993; Bristow et al., 1994; Wolf et al., 1994). We therefore thought it important to examine in detail the effects of psychostimulants and DA on excitatory synaptic transmission in the NAc. Our results demonstrate that cocaine, amphetamine, and DA each depress synaptic transmission between prelimbic cortex and cells in the core region of the NAc. In general, these results agree with previous studies which found that excitatory transmission in the NAc is reduced by DA (Yang and Mogenson, 1984; DeFrance et al., 1985b; Yim and Mogenson, 1988; Higashi et al., 1989; Pennartz et al., 1992a; O'Donnell and Grace, 1994).

An important finding of the present study is that a presynaptic mechanism seems to be responsible for the depressant action of DA and amphetamine on cortico-accumbens synaptic transmission. This conclusion follows from the finding that mEPSC frequency but not mEPSC amplitude is reduced by the application of DA or amphetamine. Consistent with this con- clusion, the magnitude of PPF at the cortico-accumbens synapse was increased by DA (see also Higashi et al., 1989; Pennartz et al., 1992a). The NAc receives excitatory inputs from several brain regions other than the prelimbic cortex (Pennartz et al., 1994), and the mEPSC distributions are likely to reflect this diversity in excitatory afferent input. Thus, the presynaptic actions of the psychostimulants and DA are probably not limited to the terminals of prelimbic afferents but may also act on other excitatory inputs to the NAc.

It is important to note that in neostriatal cells DA can modify several voltage-dependent conductances (Calabresi et al., 1987; Schiffmann et al., 1995; Surmeier et al., 1995), an effect that postsynaptically may alter the integration of synaptic potentials. DA acting on D1-like receptors has also been reported to modulate NMDA receptor-mediated currents directly (Cepeda et al., 1993). Because cells in our experiments were held at negative membrane potentials ( -80 to $-90 \mathrm{mV}$ ), such postsynaptic effects would not have been observed.

Psychostimulants block the reuptake of DA (Kuhar et al., 1991) or, as is the case with amphetamine, actively reverse the reuptake pump so that DA is released from dopaminergic terminals even in the absence of activity in the nerve terminal (Seiden et al., 1993; Sulzer et al., 1995). Thus it is not surprising that many previous studies in the NAc, both in vivo and in vitro, have also demonstrated that pyschostimulants produce effects that are similar to those of DA (Uchimura et al., 1986; White and Wang, 1986; Higashi et al., 1989; Uchimura and North, 1990; Henry and White, 1992; White et al., 1993). Anatomical studies indicate that the terminals of dopaminergic afferents to the NAc do not make axoaxonic contacts on excitatory afferents but instead form the majority of their synapses on distal dendritic spines of medium spiny neurons (for review, see Smith and Bolam, 1990). These same dendritic spines receive input from excitatory afferents (Freund et al., 1984; Sesack and Pickel, 1990), including those from prefrontal cortex (Sesack and Pickel, 1992). Thus, the psychostimulant-induced increase in extracellular DA level must be sufficient to allow DA to diffuse away from the site of direct synaptic contact and interact with presynaptic receptors on the terminals of cortical afferents, which are usually $<1 \mu \mathrm{m}$ away. Consistent with this idea is recent work in the NAc which suggests that DA routinely escapes from the synaptic cleft during dopaminergic synaptic transmission and can in fact readily diffuse to extrasynaptic sites $>1 \mu \mathrm{m}$ away (Garris et al., 1994). DA released from dopaminergic terminals in the NAc may therefore act in a paracrine fashion, similar to the extrasynaptic modulatory actions of DA in the vertebrate retina (Dowling, 1991).

The pharmacological analysis of the synaptic actions of DA and psychostimulants indicates that the receptor mediating the decrease in transmitter release may be atypical. The D1-like receptor antagonist SCH23390, but not the D2-like antagonist sulpiride, inhibited the actions of DA and amphetamine. Consistent with these results, the D2 agonist quinpirole did not depress synaptic transmission, whereas 6,7-ADTN, an agonist for both D1-like and D2-like receptors, mimicked the actions of DA and the psychostimulants. However, neither ( - -SKF38393 nor ( \pm )SKF81297 at a concentration higher than the $\mathrm{EC}_{50}$ for adenylate cyclase-coupled D1-like receptors (Andersen and Jansen, 1990) induced an appreciable depression of synaptic transmission. Furthermore, coapplication of SKF81297 and quinpirole had no significant effect (data not shown). Surprisingly, when we applied higher concentrations $(100 \mu \mathrm{M})$ of $( \pm)$-SKF38393, a synaptic 
depression, which was blocked by the D1 antagonist SCH23390, was observed.

A receptor with a similar pharmacological profile has recently been identified in striatal tissue and found to be coupled to phosphoinositide hydrolysis (Mahan et al., 1990; Undie and Friedman, 1990, 1992; Undie et al., 1994). The observed effects of psychostimulants and DA on synaptic transmission may be the result of activation of this receptor, or of the activation of a classical D1-like receptor that has been modified such that its binding to certain agonists is adversely affected. The finding of a normal effect of DA on synaptic transmission in slices from mutant mice lacking D1a receptors (Xu et al., 1994a,b), however, rules out the possibility that the D1a receptor is required. Several other D1-like receptors have been identified (Sibley, 1995), but examination of the precise role of these in the NAc will depend on the development of more specific pharmacological agents or the generation of additional knockout mice.

In addition to influencing extracellular DA levels, psychostimulants can alter the reuptake of norepinephrine and serotonin (Cunningham et al., 1992). Thus we considered the possibility that these other monoamines contributed to the observed effects of amphetamine on synaptic transmission. Both norepinephrine and serotonin were found to depress synaptic transmission in the NAc. The $\alpha$-adrenergic receptor antagonist phentolaminc, however, completely inhibited the effect of norepinephrine yet had no effect on the depression of synaptic transmission caused by amphetamine. Similarly, SCH23390 blocked the effects of amphetamine and DA but did not reduce the effects of serotonin. Thus the synaptic actions of amphetamine do not seem to involve other monoamines and are likely mediated predominantly by DA. In agreement with this conclusion, we found that lesioning the dopaminergic afferents from the VTA to the NAc with 6-OHDA (Ungerstedt, 1971) significantly reduced the effectiveness of amphetamine. The fact that the amphetamine effect was not completely abolished by injections of 6-OHDA can be attributed to incomplete lesions perhaps combined with denervation supersensitivity.

'Taken together, the present results indicate that psychostimulants and DA depress cortico-accumbens synaptic transmission by a presynaptic mechanism that involves a DA receptor with some properties in common with the D1 family, most notably antagonism by $\mathrm{SCH} 23390$. Previous investigations have yielded conflicting results concerning whether D1-like receptor activation inhibits cortico-accumbens synaptic transmission (Higashi et al., 1989; Pennartz et al., 1992a; O'Donnell and Grace, 1994). Our findings of an atypical pharmacological profile similar but not identical to the classical D1-like receptors may help to explain the diflering results. Evidence is accumulating that D1-like receptors can modulate transmitter release in several regions other than the NAc, including inhibitory synapses in the VTA (Cameron and Williams, 1993), as well as excitatory synapses in the entorhinal cortex (Pralong and Jones, 1993) and prefrontal cortex (Law-Tho et al., 1994; Williams and Goldman-Rakic, 1995). Each of these areas receives dopaminergic afferents from the VTA. Thus, one general function of the mesolimbic DA system may be to exert an inhibitory modulation of synaptic transmission in target areas via $\mathrm{SCH} 23390$-sensitive D1-like DA receptors. In contrast, DA autoreceptors, which function to modulate DA release from dopaminergic neurons, exhibit properties characteristic of D2-like receptors (Wolf and Roth, 1987).

In vivo single-unit recording has demonstrated that activation of D1 receptors in the NAc with either DA agonists or psychostimulants depresses single-unit activity (White and Wang, 1986; White et al., 1993), an effect that, like the one reported here, may not involve a classic D1 receptor (Johansen et al., 1991). Repeated administration of cocaine causes a persistent enhancement of this D1 receptor-mediated depressant effect (Henry and White, 1991). 'These results have been interpreted as being attributable to activation of postsynaptic D1 receptors and changes in their sensitivity after chronic cocaine treatment (Henry and White, 1991, 1992). The present results suggest that decreases in the level of excitatory input to the NAc attributable to activation of presynaptic D1-like receptors may also contribute to the inhibition of firing of NAc cells induced by DA and pyschostimulants in vivo.

All areas of the cerebral cortex project to the striatum topographically such that the dorsal strialum receives a predominant input from sensorimotor cortical areas and the ventral striatum (i.e., NAc) receives inputs primarily from limbic-related areas (Alexander et al., 1986; Gerfen, 1992). If as suggested by this and previous studies (Malenka and Kocsis, 1988; Surmeier et al., 1993; Hersch et al., 1995) the presynaptic action of DA to depress excitatory cortical inputs is limited to the ventral striatum, however, release of DA attributable to activity in the VTA will modify the integration of afferent information by medium spiny neurons in the NAc in a manner different from that which occurs in the dorsal striatum during activity in the substantia nigra. To determine whether this differential action of DA contributes to the behavioral and rewarding effects of psychostimulants will require a more complete understanding of the actions of DA in the NAc and dorsal striatum.

\section{REFERENCES}

Alexander GE, DeLong MR, Strick PL (1986) Parallel organization of functionally segregated circuits linking basal ganglia and cortex. Annu Rev Neurosci 9:357-381.

Andersen PH, Jansen JA (1990) Dopamine receptor agonists: selectivity and dopamine $\mathrm{D}_{1}$ receptor efficacy. Eur J Pharmacol 188:335-347.

Blanton M, LoTurco J, Kriegstein A (1989) Whole cell recording from neurons in slices of reptilian and mammalian cerebral cortex. J Neurosci Methods 30:203-210.

Bristow LJ, Thorn L, Tricklebank MD, Hutson PH (1994) Competitive NMDA receptor antagonists attenuate the behavioural and neurochemical effects of amphetamine in mice. Eur J Pharmacol 264:353-359.

Brog JS, Salyapongse A, Deutch AY, Zahm DS (1993) The patterns of afferent innervation of the core and shell in the "accumbens" part of the ventral striatum: immunohistochemical detection of retrogradely transported fluoro-gold. J Comp Neurol 338:255-278.

Calabresi P, Mecuri N, Stanzione P, Stefani A, Bernardi G (1987) Intracellular studies on the dopamine-induced firing inhibition of neostriatal neurons in vitro: evidence for D1 receptor involvement. Neuroscience 20:757-771.

Cameron DL, Williams JT (1993) Dopamine D1 receptors facilitate transmitter release. Nature $366: 344-347$.

Cepeda C, Buchwald NA, Levine MS (1993) Neuromodulatory actions of dopamine in the neostriatum are dependent upon the excitatory amino acid receptor subtypes activated. Proc Natl Acad Sci USA 90:9576-9580.

Chang HT, Kitai ST (1986) Intracellular recordings from rat nucleus accumbens neurons in vitro. Brain Res 366:392-396.

Christie MJ, Summers RJ, Stephenson JA, Cook JC, Beart PM (1987) Excitatory amino acid projections to the nucleus accumbens septi in the rat: a retrograde transport study utilizing $D-\left[{ }^{3} \mathrm{H}\right]$ aspartate and $\left[{ }^{3} \mathrm{H}\right] \mathrm{GABA}$. Neuroscience $22: 425-439$.

Chronister RB, Sikes RW, Trow TW, DeFrance JF (1981) The organization of nucleus accumbens. In: The neurobiology of the nucleus accumbens (Chronister RB, DeFrance JF, eds), pp 97-146. Brunswick, ME: Hauer Institute.

Civelli O, Bunzow JR, Grandy DK (1993) Molecular diversity of the dopamine receptors. Annu Rev Pharmacol Toxicol 32:281-307. 
Cunningham KA, Paris JM, Goeders NE (1992) Serotonin neurotransmission in cocaine sensitization. Ann NY Acad Sci 654:117-127.

DeFrance JF, Marchand JF, Sikes RW, Chronister RB, Hubbard JI (1985a) Characterization of fimbria inputs into nucleus accumbens. J Neurophysiol 54:1553-1567.

DeFrance JF, Sikes RW, Chronister RB (1985b) Dopamine action in the nucleus accumbens. J Neurophysiol 54:1568-1577.

Dowling JE (1991) Retinal neuromodulation: the role of dopamine. Vis Neurosci 7:87-97.

Dunwiddie TV, Proctor WR, Tyma J (1988) Local anaesthetic actions of cocaine: effects on excitatory and inhibitory synaptic responses in the hippocampus in vitro. Br J Pharmacol 95:1117-1124.

Freund TF, Powell JF, Smith AD (1984) Tyrosine hydroxylaseimmunoreactive boutons in synaptic contact with identified striatonigral neurons, with particular reference to dendritic spines. Neuroscience $13: 1189-1215$

Garris PA, Ciolkowski EL, Pastore P, Wightman RM (1994) Efflux of dopamine from the synaptic cleft in the nuclcus accumbens of the rat brain. J Neurosci 14:6084-6093.

Gerfen CR (1992) The neostriatal mosaic: multiple levels of compartmental organization. Trends Neurosci 15:133-139.

Goldberg LI (1972) Cardiovascular and renal actions of dopamine: potential clinical applications. Pharmacol Rev 24:1-29.

Hamilton MH, deBelleroche JS, Gardiner JM, Herberg LJ (1986) Stimulatory effect of $N$-methylaspartate on locomotor activity and transmitter release from the rat nucleus accumbens. Pharmacol Biochem Behav 25:943-948.

Hefti F, Melamed E, Sahakian BJ, Wurtman RJ (1979) Circling behavior in rats with partial, unilateral nigro-striatal lesions: effect of amphetamine, apomorphine, and DOPA. Pharmacol Biochem Behav 12:185-188.

Henry DJ, White FJ (1991) Repeated cocaine administration causes persistent enhancement of D1 dopaminte receptor sensitivity within the rat nucleus accumbens. J Pharmacol Exp Ther 258:882-890.

Henry DJ, White FJ (1992) Electrophysiological correlates of psychostimulant-induced sensitization. Ann NY Acad Sci 654:88-100.

Hersch SM, Ciliax BJ, Gutekunst C-A, Rees HD, Heilman CJ, Yung KKL, Bolam JP, Ince E, Yi H, Levey AI (1995) Electron microscopic analysis of D1 and D2 dopamine receptor proteins in the dorsal striatum and their synaptic relationships with motor corticostriatal afferents. J Neurosci 15:5222-5237.

Higashi H, Inanaga K, Nishi S, Uchimura N (1989) Enhancement of dopamine actions on rat nucleus accumbens neurons in vitro after methamphetamine pretreatment. J Physiol (Lond) 408:587-603.

Johansen PA, Hu X-T, White FJ (1991) Relationship between D1 dopamine receptors, adenylate cyclase, and the electrophysiological responses of rat nucleus accumbens neurons. J Neural Transm 86:97-113.

Kalivas PW, Stewart J (1991) Dopamine transmission in the initiation and expression of drug and stress-induced sensitization of motor activity. Brain Res Rev 16:223-244.

Karler R, Calder LD (1992) Excitatory amino acids and the actions of cocaine. Brain Res 582:143-146.

Katz B (1966) Nerve, muscle and synapse. New York: McGraw Hill.

Kelley AE, Throne LC (1992) NMDA receptors mediate the behavioral effects of amphetamine infused into the nucleus accumbens. Brain Res Bull 29:247-254.

Kombian SB, Malenka RC (1994a) Simultaneous LTP of non-NMDA and LTD of NMDA-receptor-mediated responses in the nucleus accumbens. Nature 368:242-246.

Kombian SB, Malenka RC (1994b) Modulation of excitatory synaptic transmission by dopamine and psychostimulants in the nucleus accumbens in vitro. Soc Neurosci Abstr 20:1517.

König JFR, Klippel RA (1963) The rat brain, a stereotaxic atlas of the forebrain and lower parts of the brain stem. Baltimore: Williams \& Wilkins.

Koob GF, Bloom FE (1988) Cellular and molecular mechanisms of drug dependence. Science 242:715-723.

Kuhar MJ, Ritz MC, Boja JW (1991) The dopamine hypothesis of the reinforcing properties of cocaine. Trends Neurosci 14:299-302.

Law-Tho D, Hirsch JC, Crepel F (1994) Dopamine modulation of synaptic transmission in rat prefrontal cortex: an in vitro electrophysiolog ical study. Neurosci Res 21:151-160.

Mahan LC, Burch RM, Monsma FJ, Sibley DR (1990) Expression of striatal D, dopamine receptors coupled to inositol phosphate production and $\mathrm{Ca}^{2+}$ mobilization in Xenopus oocytes. Proc Natl Acad Sci USA $87: 2196-2200$
Malenka RC, Kocsis JD (1988) Presynaptic actions of carbachol and adenosine on corticostriatal synaptic transmission in vitro. $\mathbf{J}$ Neurosci 8:3750-3756.

Malenka RC, Nicoll RA (1986) Dopamine decreases the calciumactivated afterhyperpolarization in hippocampal CA1 pyramidal cells. Brain Res 379:210-215.

Manabe T, Wyllie DJA, Perkel DJ, Nicoll RA (1993) Modulation of synaptic transmission and long-term potentiation: effects of paired pulse facilitation and EPSC variance in the CA1 region of the hippocampus. J Neurophysiol 70:1451-1459.

Martin AR (1955) Further study of the statistical composition of the end plate potential. J Physiol (Lond) 130:114-122.

Nauta WJH, Smith GP, Faull RLM, Domesick VB (1978) Efferent connections and nigral afferents of the nucleus accumbens septi in the rat Neuroscience 3:385-401.

Nestler EJ (1992) Molecular mechanisms of drug addiction. J Neurosci $12: 2439-2450$

Nicola SM, Kombian SB, Malenka RC (1995) Cocaine, amphetamine, and dopamine depress synaptic transmission in the nucleus accumbens via a presynaptic mechanism. Soc Neurosci Abstr 21:1569.

O'Donnell P, Grace AA (1993) Physiological and morphological properties of accumbens core and shell neurons recorded in vitro. Synapse $13: 135-160$

O'Donnell P, Grace AA (1994) Tonic D2-mediated attenuation of cortical excitation in nucleus accumbens neurons recorded in vitro. Brain Res 634:105-112.

O'Donnell P, Grace AA (1995) Synaptic interactions among excitatory afferents to nucleus accumbens neurons: hippocampal gating of prefrontal cortical input. J Neurosci 15:3622-3639.

Paxinos G, Watson C (1986) The rat brain in stercotaxic coordinates. New York: Academic.

Pennartz CMA, Boeijinga PH, Lopes da Silva FH (1990) Locally evoked potentials in slices of the rat nucleus accumbens: NMDA and nonNMDA receptor mediated components and modulation by GABA. Brain Res 529:30-41.

Pennartz CMA, Dolleman-Van der Weel MJ, Kitai ST, Lopes da Silva FH (1992a) Presynaptic dopamine D1 receptors attenuate excitatory and inhibitory limbic inputs to the shell region of the rat nucleus accumbens studied in vitro. J Neurophysiol 67:1325-1334.

Pennartz CMA, Dolleman-Van der Weel MJ, Lopes da Silva FH (1992b) Differential membrane properties and dopamine effects in the shell and core of the rat nucleus accumbens studied in vitro. Neurosci Lett 136:109-112.

Pennartz CMA, Groenewegen HJ, Lopes da Silva FH (1994) The nucleus accumbens as a complex of functionally distinct neuronal ensembles: an integration of behavioral, electrophysiological and anatomical data. Prog Neurobiol 42:719-761.

Pralong E, Jones RSG (1993) Interactions of dopamine with glutamateand GABA-mediated synaptic transmission in the rat entorhinal cortex in vitro. Eur J Neurosci 5:760-767.

Pulvirenti L, Swerdlow NR, Koob GF (1991) Nucleus accumbens NMDA antagonist decreases locomotor activity produced by cocaine, heroin or accumbens dopamine, but not caffeine. J Pharmacol Biochem Behav 40:841-845.

Pulvirenti L, Maldonado-Lopez R, Koob GF (1992) NMDA receptors in the nucleus accumbens modulate intravenous cocaine but not heroine self-administration in the rat brain. Brain Res 594:327-330.

Robinson TE, Berridge KC (1993) The neural basis of drug craving: an incentive-sensitization theory of addiction. Brain Res Rev 18:247-291.

Schiffmann SN, Lledo P-M, Vincent J-D (1995) Dopamine D, receptor modulates the voltage-gated sodium current in rat striatal neurones through a protein kinase A. J Physiol (Lond) 483:95-107.

Seiden LS, Sabol KE, Ricaurte GA (1993) Amphetamine: effects on catecholamine systems and behavior. Annu Rev Pharmacol Toxicol 32:639-677.

Sesack SR, Pickel VM (1990) In the rat medial nucleus accumbens, hippocampal and catccholaminergic terminals converge on spiny neurons and are in apposition to each other. Brain Res 527:266-279.

Sesack SR, Pickel VM (1992) Prefrontal cortical efferents in the rat synapse on unlabeled neuronal targets of catecholamine terminals in the nucleus accumbens septi and dopamine neurons in the ventral tegmental area. J Comp Neurol 320:145-160.

Sesack SR, Deutch AY, Roth RH, Bunney BS (1989) Topographical organization of the efferent projections of the medial prefrontal cortex 
in the rat: an anterograde tract-tracing study with Phaseolus vulgaris leucoagglulinin. $J$ Comp Neurol 290:213-242.

Sibley DR (1995) Molecular biology of dopamine receptors. In: Molecular and cellular mechanisms of neostriatal function (Ariano MA, Surmeier DJ, eds), pp 255-272. Austin: RG Landes.

Smith AD, Bolam JP (1990) The neural network of the basal ganglia as revealed by the study of synaptic connections of identified neurones. Trends Neurosci 13:259-265.

Sulzer D, Chen T-K, Lau YY, Kristensen H, Rayport S, Ewing A (1995) Amphetamine redistributes dopamine from synaptic vesicles to the cytosol and promotes reverse transport. J Neurosci 15:4102-4108.

Surmeier DJ, Reiner A, Levine MS, Ariano MA (1993) Are neostriatal dopamine receptors co-localized? Trends Neurosci 16:290-305.

Surmeier DJ, Bargas J, Hemmings Jr HC, Nairn AC, Greengard P (1995) Modulation of calcium currents by a $\mathrm{D}_{1}$ dopaminergic protein kinase/ phosphatase cascade in rat neostriatal neurons. Neuron 14:385-397.

Swerdlow NR, Koob GF (1987) Dopamine, schizophrenia, mania and depression: toward a unified hypothesis of cortico-striato-pallidothalamic function. Behav Brain Sci 10:197-245.

Uchimura N, North RA (1990) Actions of cocaine in rat nucleus accumbens neurons in vitro. Br J Pharmacol 99:736-740.

Uchimura N, North RA (1991) Baclofen and adenosine inhibit synaptic potentials mediated by $\gamma$-amino butyric acid and glutamate release in rat nucleus accumbens. J Pharmacol Exp Ther 258:663-668.

Uchimura N, Higashi H, Nishi S (1986) Hyperpolarizing and depolarizing actions of dopamine via D1 and D2 receptors on nucleus accumbens neurons. Brain Res 375:368-372.

Uchimura N, Higashi H, Nishi S (1989) Membrane and synaptic responses of the guinea pig nucleus accumbens neurons in vitro. J Neurophysiol 61:769-779.

Undie AS, Friedman E (1990) Stimulation of a dopamine D1 receptor enhances inositol phosphates formation in rat brain. J Pharmacol Exp Ther 252:987-992.

Undie AS, Friedman E (1992) Selective dopaminergic mechanism of dopamine and SKF38393 stimulation of inositol phosphate formation in rat brain. Eur J Pharmacol 226:297-302.

Undie AS, Weinstock J, Sarau HM, Friedman E (1994) Evidence for a distinct D1-like receptor that couples to activation of phosphoinositide metabolism in brain. J Neurochem 62:2045-2048.

Ungerstedt U (1971) Stereotaxic mapping of the monoamine pathways in the rat brain. Acta Physiol Scand [Suppl] 367:1-48.
White FJ, Wang RY (1984) Interactions of cholecystokinin octapeptide and dopamine on nucleus accumbens. Brain Res 300:161-166.

White FJ, Wang RY (1986) Electrophysiological evidence for the existence of both D1 and D2 dopamine receptors in the rat nucleus accumbens. J Neurosci 6:274-280.

White FJ, Hu X-T, Henry DJ (1993) Electrophysiological effects of cocaine in the rat nucleus accumbens: microiontophoretic studies. J Pharmacol Exp Ther 66:1075-1084.

Williams GV, Goldman-Rakic PS (1995) Modulation of memory fields by dopamine D1 receptors in prefrontal cortex. Nature 376:572-575.

Wise RA, Bozarth MA (1987) A psychomotor stimulant theory of addiction. Psychol Rev 94:469-492.

Wolf ME, Jeziorski M (1993) Coadministration of MK-801 with amphetamine, cocaine or morphine prevents rather than transiently masks the development of behavioral sensitization. Brain Res 613:291-294.

Wolf ME, Khansa MR (1991) Repeated administration of MK-801 produces sensitization to its own locomotor stimulant effects but blocks sensitization to amphetamine. Brain Res 562:164-168.

Wolf ME, Roth RH (1987) Dopamine autoreceptors. In: Dopamine receptors (Creese I, Fraser CM, eds), pp 45-96. New York: Liss.

Wolf ME, White FJ, Hu X-T (1994) MK-801 prevents alterations in themesoaccumbens dopamine system associated with behavioral sensitization to amphetamine. J Neurosci 14:1735-1745.

Xu M, Moratalla R, Gold LH, Hiroi N, Koob GF, Graybiel AM, Tonegawa S (1994a) Dopamine D1 receptor mutant mice are deficient in striatal expression of dynorphin and in dopamine-mediated behavioral responses. Cell 79:729-742.

Xu M, Hu X-T, Cooper DC, Moratalla R, Graybiel AM, White FJ, Tonegawa $S$ (1994b) Elimination of cocaine-induced hyperactivity and dopamine-mediated neurophysiological effects in dopamine D1 receptor mutant mice. Cell 79:945-955.

Yang CR, Mogenson GJ (1984) Electrophysiological responses of neurons in the nucleus accumbens to hippocampal stimulation and the attenuation of the excitatory responses by the mesolimbic dopaminergic system. Brain Res 324:69-84.

Yim CY, Mogenson GJ (1988) Neuromodulatory action of dopamine in the nucleus accumbens: an in vivo intracellular study. Neuroscience 26:403-415.

Zucker RS (1989) Short-term plasticity. Annu Rev Neurosci 12:13-31. 